\title{
WestVirginiaUniversity
}

THE RESEARCH REPOSITORY @ WVU

Graduate Theses, Dissertations, and Problem Reports

2003

\section{Effects of bit geometry in multiple bit-rock interaction}

Rizwan Ahmad Qayyum
West Virginia University

Follow this and additional works at: https://researchrepository.wvu.edu/etd

\section{Recommended Citation}

Qayyum, Rizwan Ahmad, "Effects of bit geometry in multiple bit-rock interaction" (2003). Graduate Theses, Dissertations, and Problem Reports. 1305.

https://researchrepository.wvu.edu/etd/1305

This Thesis is protected by copyright and/or related rights. It has been brought to you by the The Research Repository @ WVU with permission from the rights-holder(s). You are free to use this Thesis in any way that is permitted by the copyright and related rights legislation that applies to your use. For other uses you must obtain permission from the rights-holder(s) directly, unless additional rights are indicated by a Creative Commons license in the record and/ or on the work itself. This Thesis has been accepted for inclusion in WVU Graduate Theses, Dissertations, and Problem Reports collection by an authorized administrator of The Research Repository @ WVU. For more information, please contact researchrepository@mail.wvu.edu. 


\title{
Effects of Bit Geometry in Multiple Bit-Rock Interaction
}

\author{
Rizwan A. Qayyum \\ Thesis Submitted to the \\ College of Engineering and Mineral Resources \\ at West Virginia University \\ in partial fulfillment of the requirements \\ for the degree of \\ Master of Science \\ in \\ Mining Engineering
}

\author{
Abdul Wahab Khair, Ph.D., Chair \\ Syd S. Peng, Ph.D. \\ Y. Luo, Ph.D.
}

Department of Mining Engineering

\author{
Morgantown, West Virginia \\ 2003
}

Keywords: Bits, Bit geometry, Respirable dust, Bit spacing, Continuous miners.

Copyright 2003 Rizwan A. Qayyum 


\section{Abstract \\ Effects of Bit Geometry in Multiple Bit-Rock Interaction}

\section{Rizwan A. Qayyum}

The impact of bit-coal/rock interaction during the cutting process in underground mines is great concern to the mining community of the world. Rock/coal cutting bears directly on rock/coal dust generation that causes "black lung/silicosis" in miners. On the other hand, rock cutting generates radiance of sparks that has potential to cause face ignition. Bit wear affects productivity, safety and economy. Hundreds of face ignitions and millions of dollars in productivity and compensation for respirable rock/coal dust related diseases are attributed to the cutting action of continuous miners/shearers. These undesirable impacts could be minimized by proper selection of bit types, bit design, cutting parameters of the cutting head, and amount of water and position of water jets. This thesis evaluates the effects of bit geometry in multiple bits - rock interaction, utilizing an automated rotary coal cutting simulator (ARCCS) and synthetic rock. Five types of bit/cutting tool with different cone and tip geometry were tested against the synthetic rock of 16 " x 14 " x 4 " dimension. The rotation of the cutting drum was kept at $100 \mathrm{rpm}$ and the cutting drum was advanced at $0.14 \mathrm{in} / \mathrm{sec}$ of advance. Cutting force, penetration force, rate of advance and respirable dust were measured during the cutting process. Specific energy and specific dust were also calculated for each experiment. 


\section{Acknowledgments}

As many before me have noted, completing a thesis requires the cooperation and support of many individuals. To mention everyone who contributed to this undertaking would be difficult. I have thus decided to limit my acknowledgements to those who inspired much of what I have done, those who helped me in my endeavor, and to those who encouraged me during those times when the completion of the task seemed far away.

I would like to express my sincere gratitude to my academic advisor Dr. A. Wahab Khair. Without his knowledge, guidance and previous experience this research would not have been possible. I would like to convey my thanks and appreciation to the other committee members, Dr. Syd S. Peng and Dr. Yi Luo for their ideas and inspiration.

This research has been supported by Coal and Energy Research Bureau (CERB), I am thankful for their financial support during the course of this research work. Special Thanks to Mr. Bo Yu for his help in the experimental work, Ms. Karen Centofanti for her assistance in the official work. I would like to express to all my friends who helped me in many ways during my stay in Morgantown.

Finally I am greatly indebted to my parents whose support and help can never be expressed in words. 
To My Parents 


\section{Table of Contents}

$\begin{array}{lll}\text { Content } & \text { Page }\end{array}$

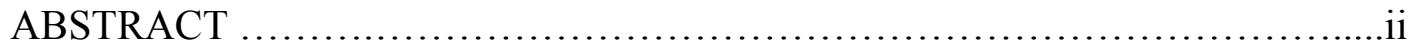

ACKNOWLEDGMENTS...................................................ii

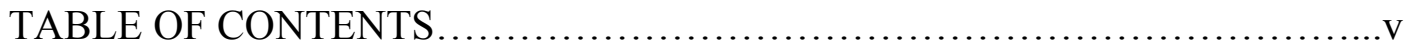

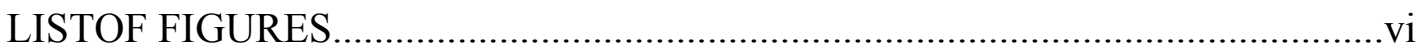

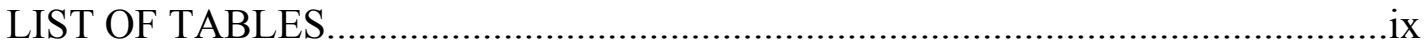

\section{Chapter 1}

1.1 INTRODUCTION................................................... 1

\section{Chapter 2}

2.1 LITERATURE REVIEW............................................... 3

\section{Chapter 3}

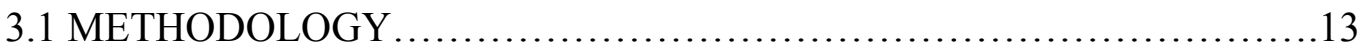

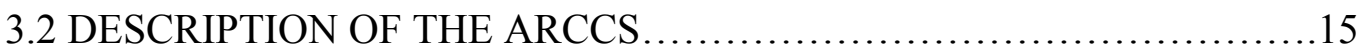

3.3 SYNTHETIC MATERIAL …......................................... 19

3.4 PHYSICAL AND MECHANICAL PROPERTIES OF SYNTHETIC MATERIAL ...................................................................... 19

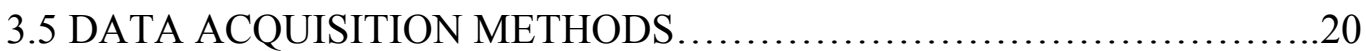

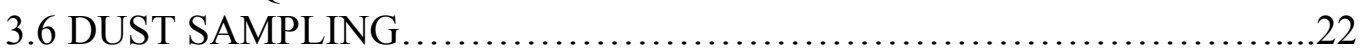

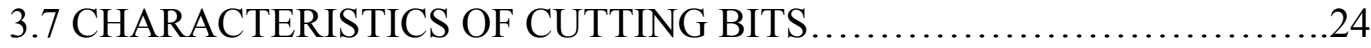

3.8 ROCK CUTTING EXPERIMENTS.................................. 31

\section{Chapter 4}

4.1 RESULTS AND ANALYSIS..........................................

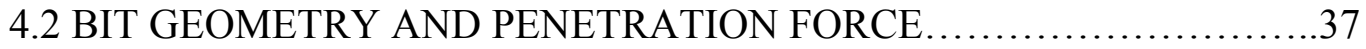

4.3 BIT GEOMETRY AND CUTTING FORCE ........................... 37

4.4 RESULTANT FORCES............................................ 37

4.5 BIT GEOMETRY AND SPECIFIC DUST ............................. 38

4.6 BIT GEOMETRY AND SPECIFIC ENERGY ......................... 38

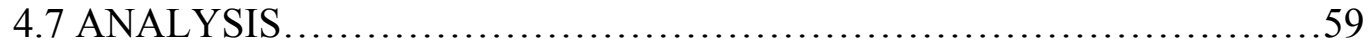

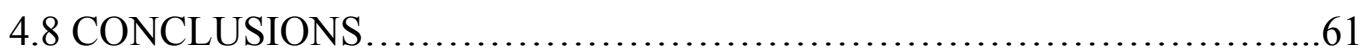

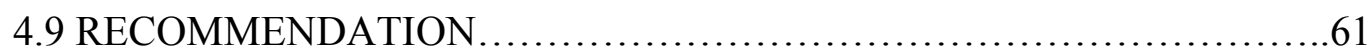




\section{LIST OF FIGURES}

Figure 2.1. Test and Monitoring equipment facilities $\quad 8$

Figure 2.2. Typical specimen located in the confining chamber and ready for experiment.

Figure $2.3 \mathrm{a}-\mathrm{c}$. Coal blocks cut with different cut spacing.

a. 3 in. spacing face cleat, b. 1.5 in. spacing face cleat, c. 1.5 in. spacing butt cleat

$\begin{array}{lr}\text { Figure 2.4. Typical experimental setup } & 10\end{array}$

Figure 2.5. Photograph of the cut surface, tested Godula sandstone block. $\quad 10$

Figure 2.6. cut surface of the rock at $12 \quad 11$

Figure 2.7. Cut surface of the rock at $18 \mathrm{~mm}$ and $9 \mathrm{~mm}$ depth of cut utilizing US2 bit depth of cut, utilizing US2 bit.

Figure 2.8. Variation of mean normal force/mean cutting force with increasing depth of cut

Figure 2.9. Variation of mean peak normal force/mean peak cutting force with increasing depth of cut

Figure 2.10. Variation of specific energy with depth of cut 12

Figure 3.1. Automated Rotary Cutting Simulator (ARCCS) 15

Figure 3.2 . Control Panel of Automated Rotary Cutting Simulator (ARCCS) 18

Figure 3.3 . Data Acquisition System of Automated Rotary

Cutting Simulator (ARCCS)

Figure 3.4. Cascade Impactor assembly 23

Figure 3.5. Bit A (Bit with the largest tip) 25 
Figure 3.6. Bit B (Bit with medium size tip) 26

Figure 3.7 . Bit C (bit with small size tip) 27

Figure 3.8. Bit D (Bit with ridges/groves on the tip) 28

$\begin{array}{llr}\text { Figure 3.9. Bit U76K } & 29\end{array}$

Figure 3.10. All bits used in this study compared 30

Figure 3.11 . Experimental Setup 32

Figure 3.12 . Multiple Cutting in the specimen block (Bit C) 33

Figure 3.13 . Multiple Cutting in the specimen block (bit B) 34

Figure 3.14 . Multiple Cutting in the specimen block (Big A) 35

Fig 4.1 Graph showing penetration force for bit A 40

Fig 4.2 Graph showing cutting force for bit A 41

Fig 4.3 Graph showing resultant force for bit A $\quad 42$

Fig 4.4 Graph showing penetration force for bit B 43

Fig 4.5 Graph showing cutting force for bit B 44

Fig 4.6 Graph showing resultant force for bit B 45

Fig 4.7 Graph showing penetration force for bit C 46

Fig 4.8 Graph showing cutting force for bit C 47

Fig 4.9 Graph showing resultant force for bit C 48

Fig 4.10 Graph showing penetration force for bit D 49

Fig 4.11 Graph showing cutting force for bit D 50

Fig 4.12 Graph showing resultant force for bit D 51

Fig 4.13 Graph showing penetration force for bit U76K 52

Fig 4.14 Graph showing cutting force for bit U76K 53 
Fig 4.15 Graph showing resultant force for bit U76K 54

Fig. 4.16 Graph showing penetration force for all bits 55

Fig. 4.17 Graph showing cutting force for all bits 56

Fig. 4.18 Graph showing resultant force for all bits $\quad 57$

Fig. 4.19 Graph showing specific dust for all bits $\quad 58$

Fig. 4.20 Graph showing the specific energy for all bits 59 


\section{LIST OF TABLES}

Table2.1. Criteria for Repairable Dust $\quad 4$

Table 3.1. Components of the synthetic material 19

Table 3.2. Physical and Mechanical Properties of the material 20

Table 3.3. Different stages and their GMD in a cascade impactor 23 


\section{CHAPTER 1}

\subsection{Introduction:}

The high demand for coal production has increased the need for mechanical coal cutting and roof support in underground coal mines. On the other hand our coal reserves are shrinking, forcing operators to mine thin coal seams and subsequently to cut roof/floor rocks in order to maintain sufficient clearance for equipment. At the present time approximately 57 longwall faces and more than 2000 continuous miners are in operation. Enormous miles of entries are developed by these continuous miners for longwall operations as well as room and pillar mining. The amount of silica and respirable dust generated by excavating coal and cutting roofs with continuous miners is the major concern for the industry. A U.S. Government printing office stressed that every year more than 250 workers in the U.S. will die form silicosis and more than 1 million U.S. workers are exposed to crystalline silica. Unfortunately, coal mine operations contribute significantly to these statistics.

The continuous mining machines, which were introduced in 1950s, now account for approximately half of the coal production from the underground mines. Unfortunately, these continuous miners, which were designed for increasing productivity, have also increased the concentration of respirable dust in the mines. Dust control techniques such as conventional water sprays and dust collectors are only partially effective and require additional equipment expenditures. A better approach would be to reduce respirable dust at the sources, the continuous mining machine cutting head/drum, where the fragmentation process occurs. Improving the fragmentation process by understanding the 
mechanisms of coal/rock breakage will not only reduce respirable dust at the face, it will also reduce dust liberated during the secondary handling such as loading and transportation etc. 


\section{Chapter 2}

\subsection{Literature Review}

Research conducted by USBM (1) showed that the most significant underground quartz dust source was found in the continuous miner section where the miners are excavating rock. Another interesting result derived from this study (1) was that quartz dust generation and its size characteristics are affected by the morphology of the quartz bearing rock. Furthermore, the free silica bonding matrix in the rock is most likely responsible for quartz dust produced mechanical comminution.

According to Kissel's (2) observation, 73\% of dust generated from continuous miner, $25 \%$ from bolter, and $2 \%$ from beltway. If the continuous miner is cutting roof, floor or rock partings the amount of silica dust generated is beyond of an acceptable limit.

Repairable dust is defined by the criteria given in Table 2.1 (3). From table 1 it is obvious that less than $10 \mu \mathrm{m}$ particles reach the alveolar region, whereas $50 \%$ of the 3.5 $\mu \mathrm{m}$ particles reach the alveolar regions, and so on. 
Table2.1. Criteria for Repairable Dust (3)

\begin{tabular}{|c|c|c|}
\hline Aerodynamic diameter $(\mu)$ & Percent respirable USAEC & $\begin{array}{l}\text { Percent passing section, } \\
\text { ACGIH }\end{array}$ \\
\hline$<2.0$ & 100 & 90 \\
\hline 2.5 & 75 & 75 \\
\hline 3.5 & 50 & 50 \\
\hline 5.0 & 25 & 25 \\
\hline 10.0 & 0 & 0 \\
\hline
\end{tabular}

A message from the Secretary of Labor says, "if it's silica it's not just dust" (4). The mining community has centered its attention on achieving two goals; first to minimize energy required for cutting operation and second to decrease the amount of respirable dust generated during the cutting process. Unfortunately these tasks have not been met successfully. There is a need to understand the mechanism of coal/rock breakage. One of the primary factors influencing mechanical comminution of rock/coal cutting is selection of proper cutting tool. $(5,6,7,10,11,13,14)$.

Since the introduction of continuous miners in 1950's, much work has been done to improve the phenomenon of the cutting tool. In a rotary cutting action the shape of the groove along the path of an individual bit resembles a crescent moon. Each bit on the drum starts the cutting face from zero depth of cut and as the bit penetrates further in the face, the depth of cut increases to a maximum at the center line of the path of each cutting bit, then the depth of cut decreases to zero when the bit exits the cutting face. Researchers in USBM addressed the problem of non-linier cutting action of the rotary cutting drum (15). In this study a linear cutting concept was developed from the analysis of rotary technology. The liner cutting drum cuts material to an open face most of the time with minimal secondary fragmentation (15). The liner cutting drum did not get out of the 
laboratory because of two major reasons: a) the concept was totally unfamiliar to the mining industry; b) the drum required high torque gear box to be practically utilized.

In the past, enormous research has been carried out to select the design parameters for cutting tools on a trial and error basis (11). The mining industry is yet to receive a solution, which could provide optimum parameters for coal/rock cutting in underground coal mines. A few metals were tested at USBM (11) for their incendivity in methane air explosive mixtures. The results have suggested that materials like polycarbonate resin, an ultra high molecular weight polyethylene, and zinc alloys were potential metals that could be used. But these were not acceptable of holding the carbide tips during coal/rock cutting. Nickel-based alloys proved to be safer than iron based alloys as far as ignition was concerned. Research continued to find proper bit tip to prolong the life of the bit and reduce friction ignition. There are two shapes of cutting bits commonly utilized, namely, wedge type and point attack type. Although point attack type bits are used more frequently in the US, research indicates point attack bits suffer a lot of bit tip wear and damage (6). This is largely due to their inefficient rubbing contact with the wall of the cut grove (ridges/lands) as they profile.

Bit wear can be defined as the removal of material from the surface as a result of mechanical action. The mechanism of bit wear can be adhesion, abrasion, oxidation, or diffusion depending on cutting conditions. A study carried out to study the principles of bit wear and dust generation (6). In this study, four types of point attack/ conical used bits were obtained from different underground coalmines. The analysis showed that many bits did not rotate properly during cutting. The intention of using conical bits in the United 
States coal mining was to keep bit tip sharp, it should wear symmetrically, as it rotates during the cutting process. As rock and coal debris plunge into the spacing between the bit blocks and bits, lock in of the bit into the bit block results. A study showed that worn bits with $15 \%$ weight loss generated about $26 \%$ more dust than the new bits(16). Researchers at USBM (11) indicated that the rate and form of bit wear highly depend on bit temperature. Bit velocity is the main parameter to influence the bit temperature. The wear rate of steel, stellate and carbide tools is reported to be independent of bit velocity when the bit velocity is below a critical value of 165 to $220 \mathrm{ft} / \mathrm{min}$. Wear was observed to increase very rapidly above the critical velocities (11). Since bit velocity increases the temperature of the bit, it is necessary to ensure that bit velocity is below the critical value. However, low bit velocity will reduce production. A practical approach is to keep the temperature of the bit below the critical value at higher velocity (11).

Research work was conducted by a number of people on rotary cutting bits. Research at USBM (10) demonstrated that the specific energy and airborne dust (ARD) decrees significantly as the cutting depth increases and the optimum tool spacing to cutting depth ratio ranges from 2 to 3 . Further study by the USBM researchers (10) concluded that different bit do not affect the ARD as significantly as cutting depth or specific energy, but various bits have different forces and energy requirements necessary to maintain a prescribed cutting depth.

Barker (12) and Pomeroy and Brown (13) reported that optimum spacing depends on the depth of cut. For a cut spacing at which neighboring grooves interacts, the cutting forces decrease after reaching a maximum. The maximum normally corresponds to the 
condition of high product volume, low specific energy and low dust generation. Research also indicates that specific energy decreases with depth and spacing.

Many studies have addressed the influences on respirable dust generation during coal cutting process. Research was conducted at WVU (5) utilizing a series of single and multiple bit experiments on coal using a laboratory scale cutting machine in order to investigate the sources of respirable dust generation both at macro and micro levels. The Bureau of Mines conducted a series of experiments using four different coal types to determine the effect of attack angle and asymmetric bit wear on airborne respirable dust (ARD) generated by point attack bits in energy consumption (10). They established that the depth of cut has significant effect on the respirable dust and specific energy.

Research conducted at WVU indicates that specific respirable dust increased with increasing bit space in rotary cutting. As the bit spacing increases the grooves made by the bits do not interact and hence the ridges do not break. Instead of the formation of major chips, regrinding occurs in the grooves producing significant amount of fine dust. A series of preliminary laboratory experiments were carried out at the Department of Mining Engineering at WVU (5). Figure 2.1, shows experimental set up, figure 2.2, shows test coal block, Figure 2.3a-c shows tested coal blocks in different cleat directions and bit spacing. In this study a series of experiments were run with $7.62 \mathrm{~cm}$ (3in) spacing. Three bits were mounted in an echelon pattern and a 6.35-7.62 cam (2.5-3.0in) deep cut was made without breaking the boundary walls/ledges between the bit paths (see Figure 2.3a). this series of tests were carried out for the $15^{\circ}, 30^{\circ}, 45^{\circ}$, and $60^{\circ}$ attack angles. 


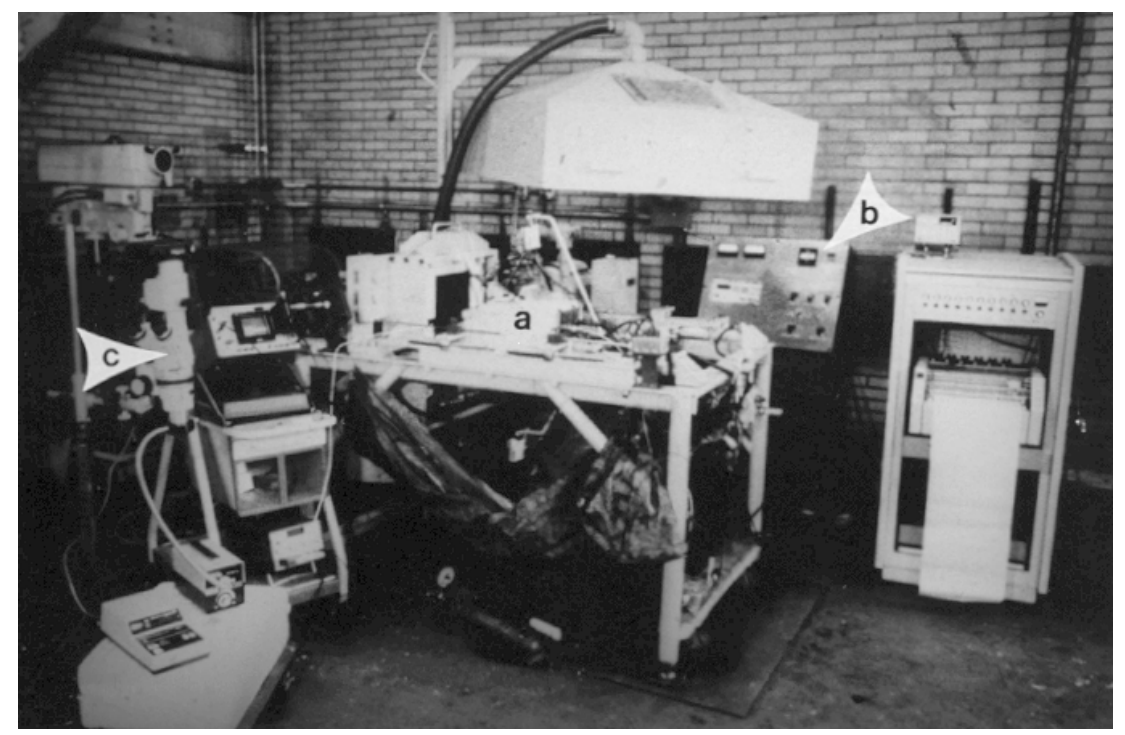

Figure 2.1. Test and Monitoring equipment facilities.

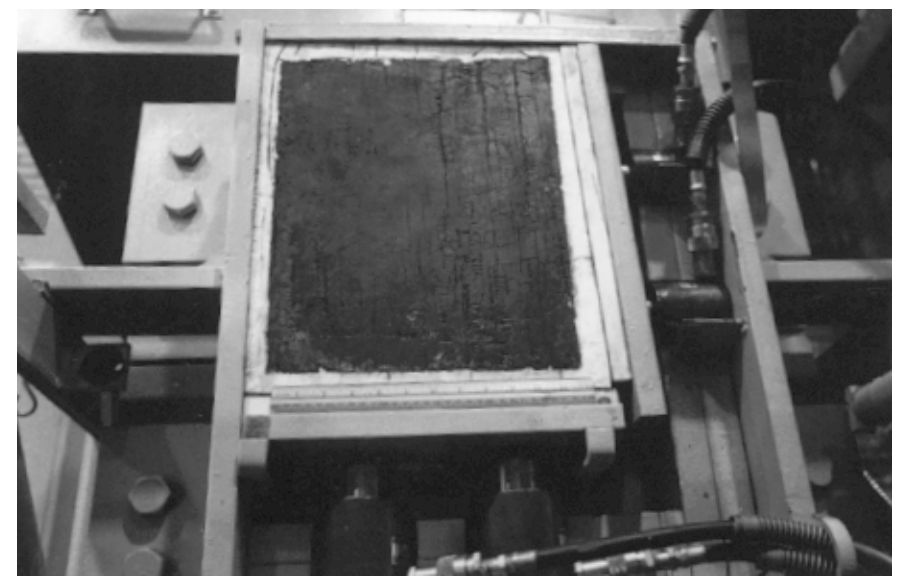

Figure 2.2. Typical specimen located in the confining chamber and ready for experiment. 

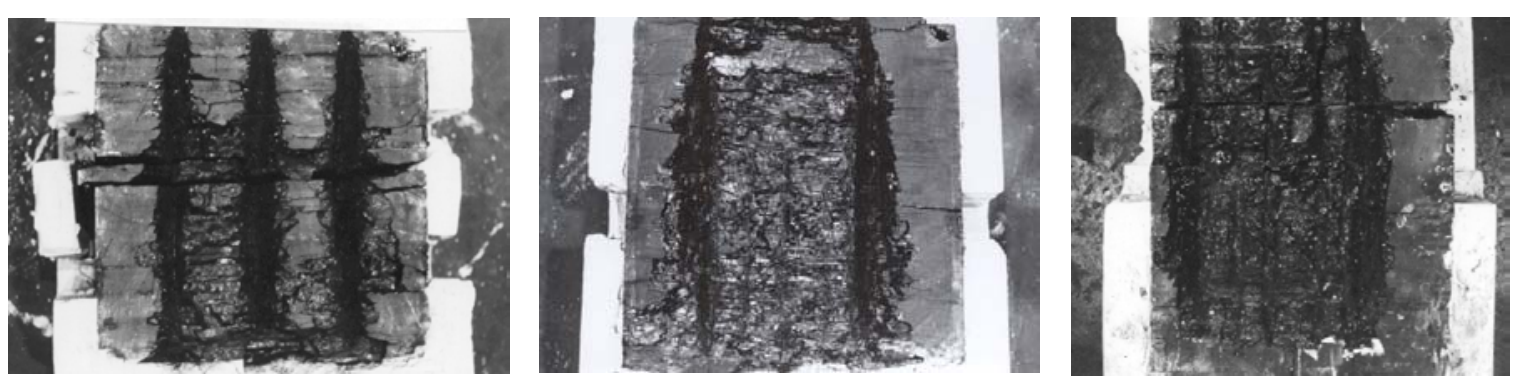

Figure $2.3 \mathrm{a}$ - c. Coal blocks cut with different cut spacing. a. 3 in. spacing face cleat, b. 1.5 in. spacing face cleat, c. 1.5 in. spacing butt cleat

With a $3.80 \mathrm{~cm}(1.5 \mathrm{in})$ spacing and five bits mounted in an echelon pattern, the side walls/ridges of the bit path were broken when the coal blocks were tested in both face and butt cleat direction (see Figures $2.3 \mathrm{~b}$ and 2.3c). In these experiments the fracture surface was more regular when tested against butt cleat, walls/ ridges between the cutting paths broke only partially and irregularly (see Figure $2.3 \mathrm{c}$ ). A total breakage of the walls/ridges created a free face (see figure 2.3b), thus reducing the required resultant forces to cut the coal (5). As it was indicated earlier that depth of cut not only reduces primary and secondary dust generation, but also reduces required specific energy, depending on bit geometry. A series of preliminary experiments were carried out at the Academy of Sciences of Czech Republic, institute of Geonics, Ostrava, Czech Republic (7). Figure 2.4 shows typical experimental setup and Figure 2.5 shows tested rock utilizing bits of different geometry. 

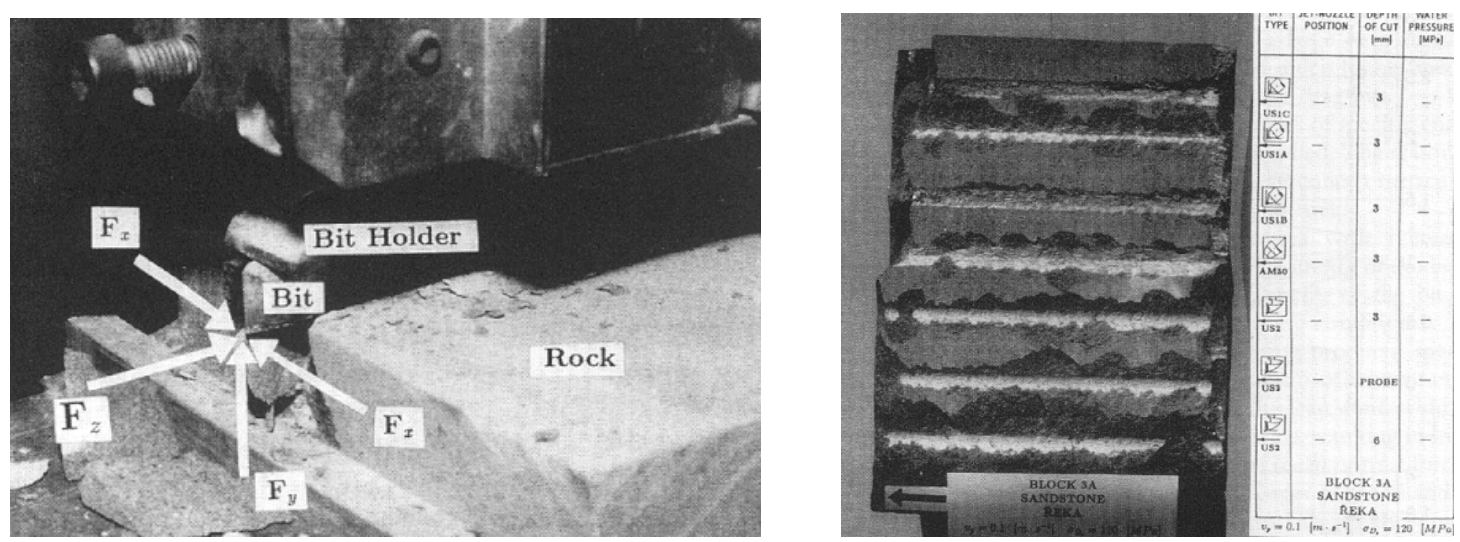

Figure 2.4. Typical experimental setup

Figure 2.5. Photograph of the cut surface, tested Godula sandstone block.

Among the tested bits, US2 performed very well. The author has indicated that this high performance of the US2 type bit was due to two geometric parameters, namely high clearance angle and prism shape of the cutting face of the bit, which further reduced the surface contract area of the bit during the cutting process. These two factors reduced the specific energy consumption for the bit, in particular, under deeper cutting condition (i.e., at a $3 \mathrm{~mm}$ depth of cut, specific energy consumed by the bit was $18.4 \mathrm{MJ} / \mathrm{m}^{3}$ with a corresponding mean nominal force to mean cutting force ratio of 0.91 and 0.53 , respectively). Results also indicated that specific energy consumed by the bit decreased with depth of cut. The damaged surfaces of the rock corresponding to different depth of cut are present in Figures 2.6 and 2.7. 


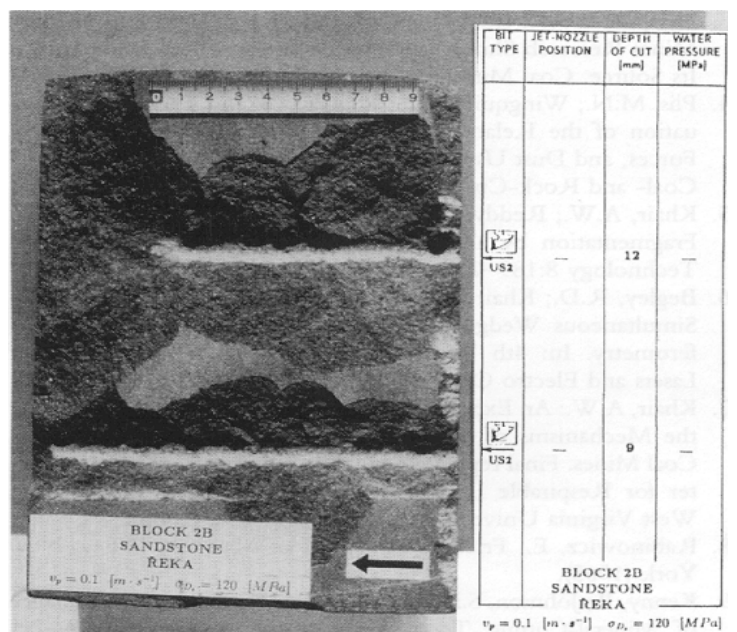

Figure 2.6. cut surface of the rock at 12 mm and 9mm depth of cut utilizing US2 bit
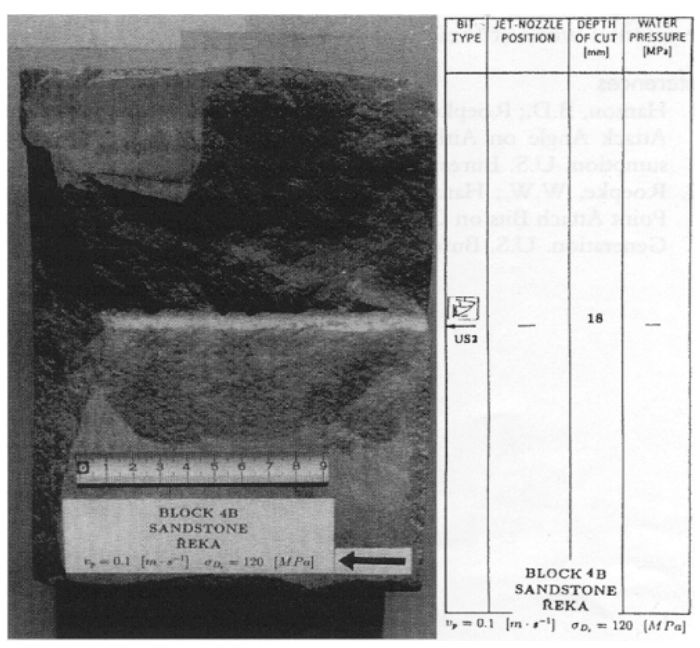

Figure 2.7. Cut surface of the rock at 18 depth of cut, utilizing US2 bit.

In deeper cutting most of the energy was consumed in the fragmentation process rather that grinding material, hence resulted in a larger product size and fewer fine particles (see Figures 2.8-2.10).

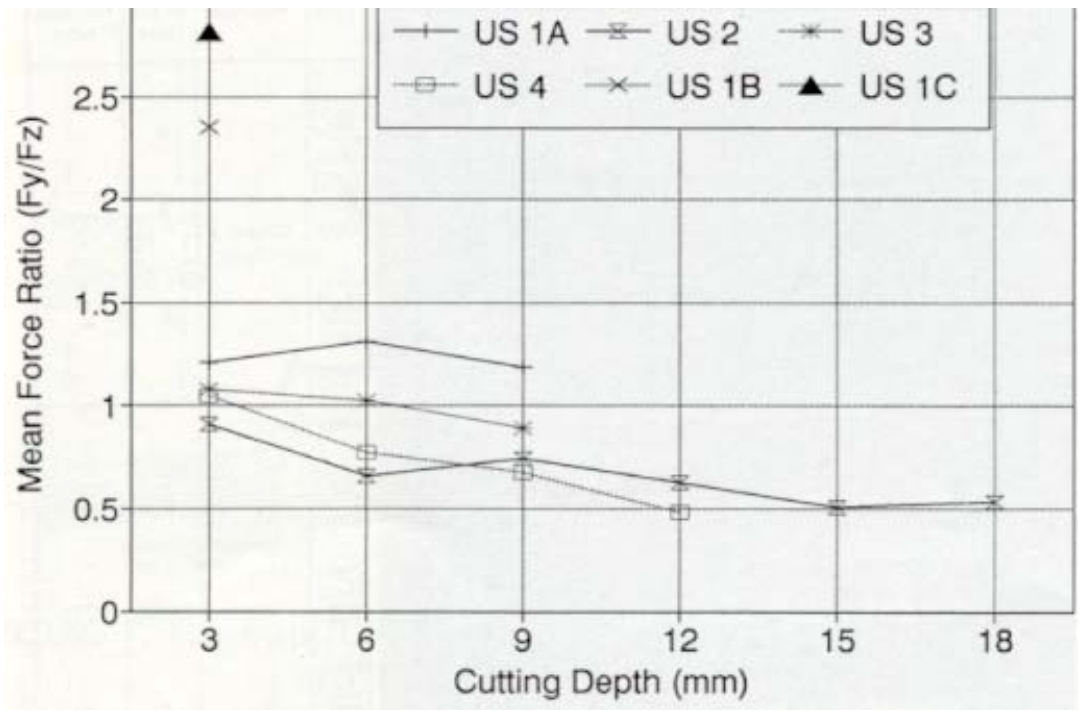

Figure 2.8. Variation of mean normal force/mean cutting force with increasing depth of cut (7). 


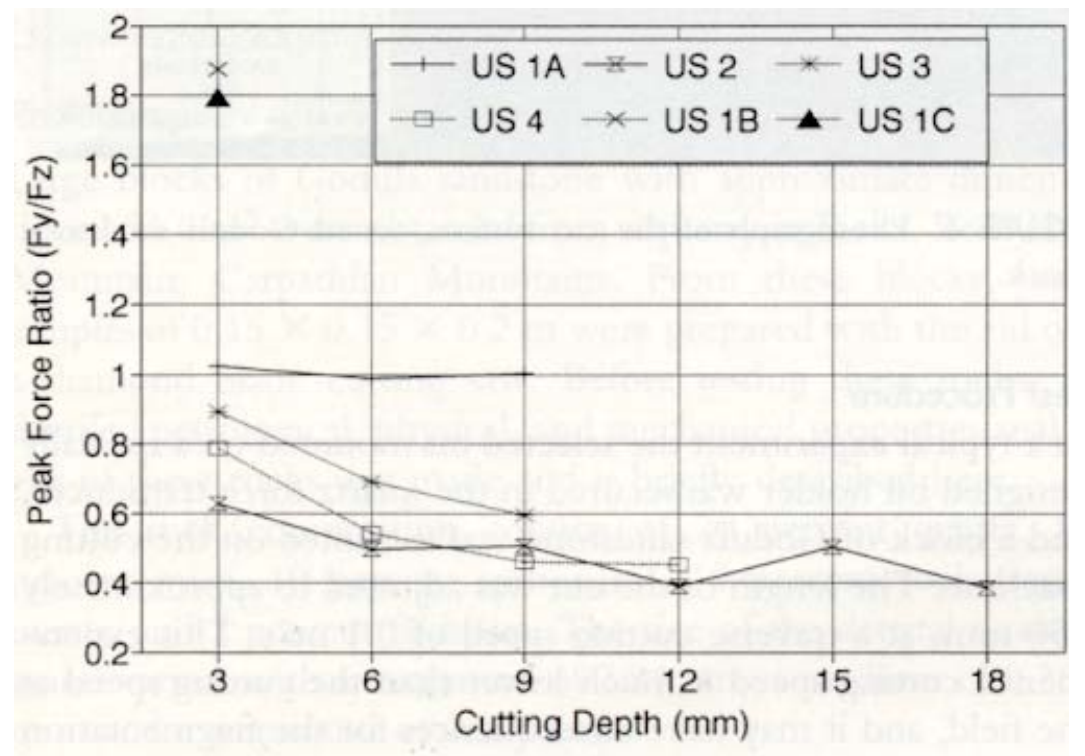

Figure 2.9. Variation of mean peak normal force/mean peak cutting force with increasing depth of cut (7).

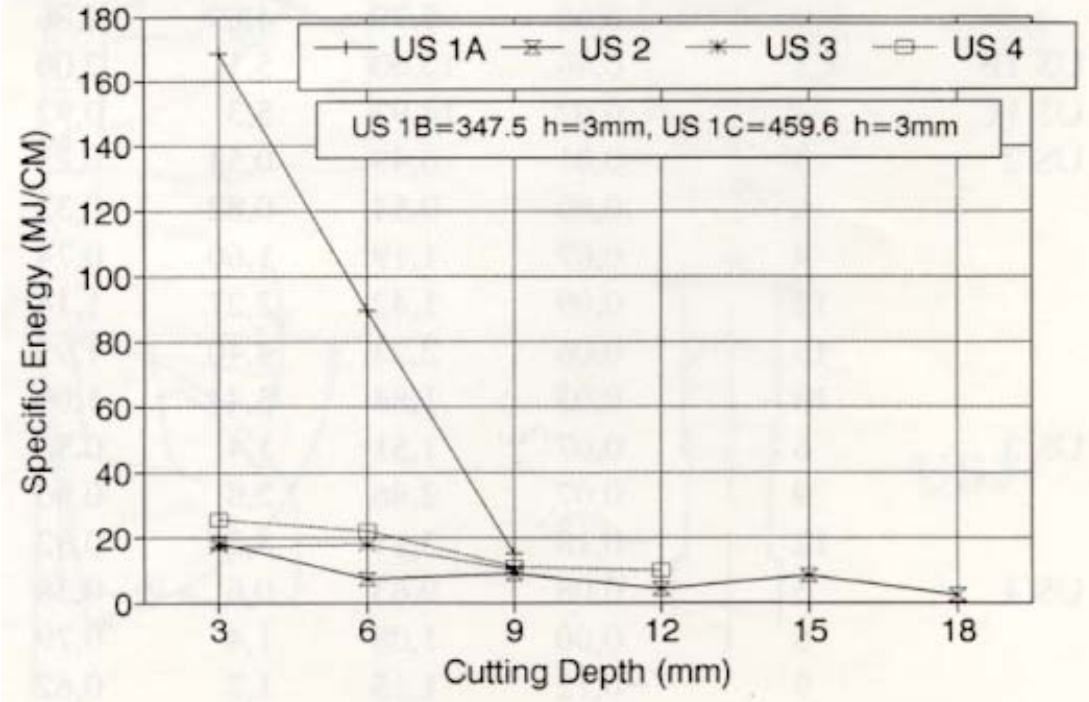

Figure 2.10. Variation of specific energy with depth of cut (7) 


\section{Chapter 3}

\subsection{Methodology}

One of the major problems in continuous miner head/drum is mainly associated with bit/tool geometry. As the bits/tools tips and bodies are not designed properly, resulting in inefficient performance of machine and tools producing high level of noise, fine particles and generating enormous amount of respirable dust. In a typical continuous miner drum, the bits cut face and their cutting ability mainly depend on the geometry of the bits. A proper design of the bit, which fragments the cutting face with least abrasive contact with the surrounding rock/coal, is essential (17). This design not only increases their cutting efficiency and wearing life it would also reduce respirable dust generation significantly. At present time the bits on drum act individually as cutting on a solid face without least interaction between the bits. The land/ridges between the bits often remains on the cutting face and results in abrasive action of the bit bodies with lands. Eventually the bit blocks will crush these lands. The interaction of the bit body with the lands and crushing of the lands by the bit blocks is the major source of respirable dust generation (25). An optimum bit tip design and stream lining of bit tip and body will increase the cutting efficiency of the bit and reduce both cutting noise and respirable dust generation (17).

In this research five conical bits are used to study and compare their effectiveness to reduce the amount of energy consumed and to reduce the specific dust produced. These bits are named as Bit A, Bit B, Bit C, bit D and U76K. The details of these bits and the 
pictures are given in the section 3.7. Out of those five bits, one bit i.e. the bit U76k has been widely used in the industry and has proved its worthiness in terms of specific energy consumption and the amount of specific dust generated in the previous researches (24, $25,28)$.

The continuous mining machines employ rotary cutting techniques. The main cutting parameters that influence the cutting efficiency of a continuous miner include bit spacing, depth of cut, bit geometry (16).

For the purpose of current studies an Automated Rotary Cutting Simulator (ARCCS) shown in the Figure (3.1) was used. This simulator enables the experimenter to simulate the in situ vertical and horizontal confining pressures and vary several other operating parameters like the depth of cut, cut spacing, velocity to the cutting head etc. Detailed description of the ARCCS is given in (24); some of the important aspects of the experimental process and the monitoring system are given. 


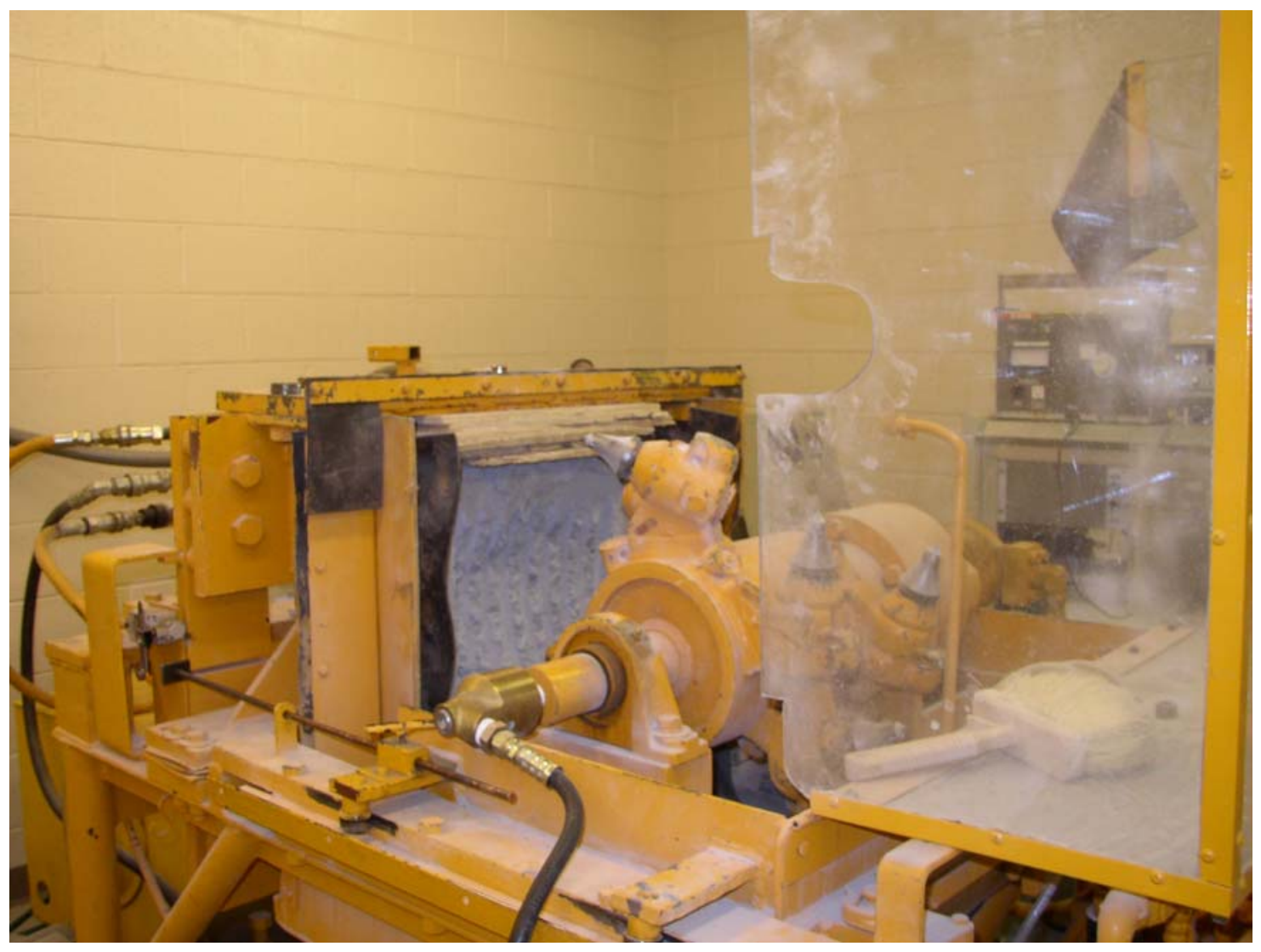

Figure 3.1. Automated Rotary Cutting Simulator (ARCCS)

\subsection{Description of the ARCCS}

A brief description of the major parts of the ARCCS is given in the following sections.

\section{Main Frame:}

The machine is mounted on a rectangular frame of $1.5 \mathrm{~m} \times 1.1 \mathrm{~m}$ side dimensions and four legs. The legs are provided with the wheels for easy maneuverability. 


\section{Confining Chamber:}

The confining chamber is made of 1in. thick steel. Inside dimension are $76.2 \mathrm{~cm} \times 50.8 \mathrm{~cm}$ $\mathrm{x} 17.78 \mathrm{~cm}$ (30in $\mathrm{x} 20 \mathrm{in} \times \mathrm{in})$. the confining pressure to the blocks of material is applied by four hydraulic cylinders. Two of these were of 10 ton capacity each (which( apply horizontal pressure), and the other two were of 20 ton capacity ( which apply vertical pressure). Hydraulic pressure to the cylinders was applied by two manually operated hydraulic pumps.

\section{Cutting drum:}

The cutting drum is $17.78 \mathrm{~cm}$ (7.0 in) in diameter and $30.5 \mathrm{~cm}$ (12in.) in width. Depending on the height of the bit block, which is made to conform to certain predetermined bit attack angels, the tip to tip diameter varies virtually with each type of cutting bit. The metered hydraulic fluid flow gives the flexibility to rotate the drum at different rotations per minute (1 to $100 \mathrm{rpm}$ ) and to advance the drum into coal at any rate or 0 to $10.2 \mathrm{~cm}$ (3 in). Power for the rotation of the drum is provided by a hydraulic motor the motor has a continuous torque of 99 joules ( $73 \mathrm{ft} .-1 \mathrm{bs})$ and a peak torque of 153 joule (113 ft.-lbs). With a 20:1 speed reduction ratio, the drum shaft attains a peak torque of 3051 joules (2250 ft.-lbs) Advancing and retreating of the cutting drum is accomplished by four hydraulic cylinders, two for advancing and two for retreating. These cylinders have a piston diameter of $2.5 \mathrm{~cm}(1 \mathrm{in}$.$) and a stroke of 15.2 \mathrm{~cm}(6 \mathrm{in}$.). The pistons of the two hydraulic cylinders which are located at the operator end, one each on either side of the main frame push and retreat the movable frame on which the drum and the motor is mounted. 
Other important parts of the ARCCS are the movable frame arrangements, air current generating unit, automated control and monitoring system. Apart form being able to operate manually the ARCCS can also be operated automatically. This system allows one to operate the drum rotation clockwise and anticlockwise. Also the frame with the drum can be pushed forward and backward to a predetermined distance. These functions can also be performed at the same time depending upon the experimental design. The control panel is shown in fig. 3.2 


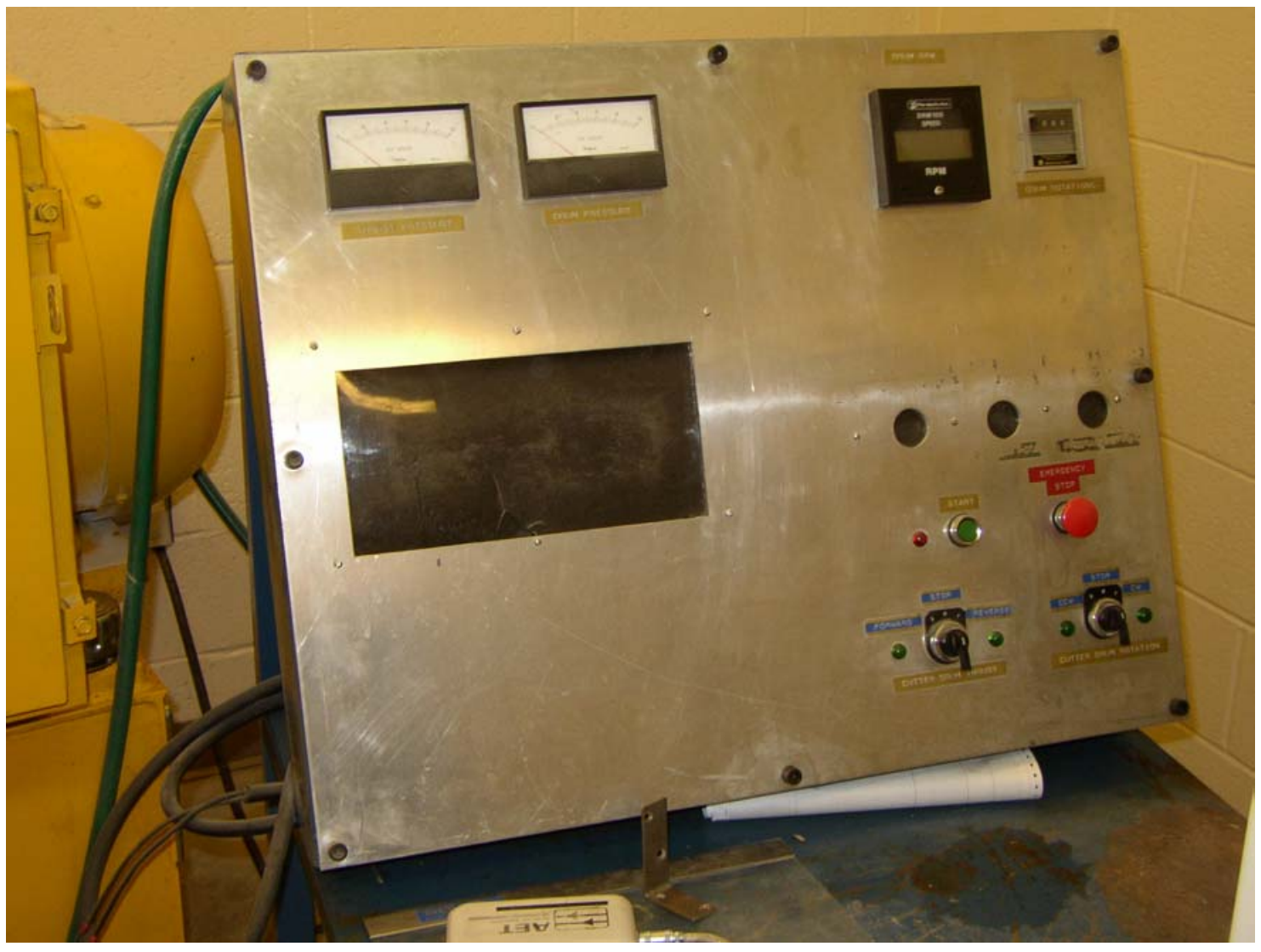

Figure 3.2 . Control Panel of Automated Rotary Cutting Simulator (ARCCS) 


\subsection{Synthetic Material}

A synthetic material with known physical properties was used for this study. This material was composed of the following ingredients. There were two attempts made to formulate this material and the ratio of composing components in each try is given in the table 3.1. The material in first attempt was very soft and was not representative of the actual coal/rock situation. The ratios of the components were changed to get a better material in the second attempt.

Table 3.1. Components of the synthetic material

\begin{tabular}{|c|c|c|c|}
\hline Components & Sand & Cement & Gypsum \\
\hline $1^{\text {st }}$ attempt & 10 & 1 & 1 \\
\hline $2^{\text {nd }}$ attempt & 5 & 1 & 0.5 \\
\hline
\end{tabular}

The ingredients were thoroughly mixed and blended before water was added. The mixed material was then poured down into wooden moulds (161/4" x 141/4" x 41/4") and allowed to dry up and gain the strength for 3 weeks from mixing.

\subsection{Physical and Mechanical properties of Synthetic Material:}

The experimental synthetic material was molded into wooden moulds to yield the blocks with a uniform dimension of (16" x 14 " $\mathrm{x} 4$ ") to suit the testing conditions of the confining chamber of the ARCCS. The cutting bits were mounted on the cutting head and the attack angle of the bit was kept at $45^{0}$ for all experiments. The material was created in a controlled environment so that all the blocks posses the same physical and mechanical properties. Table 3.2 describes the physical and mechanical properties of this material obtained in the laboratory through standard test procedures. 
Table 3.2. Physical and Mechanical Properties of the material

\begin{tabular}{|c|c|c|}
\hline Material Property & $\mathbf{1}^{\text {st }}$ Attempt & $\mathbf{2}^{\text {nd }}$ Attempt \\
\hline $\begin{array}{c}\text { Unconfined Compressive } \\
\text { Strength, psi }\end{array}$ & 302 & 505 \\
\hline Young's Modulus, psi & 35450 & 47150 \\
\hline $\begin{array}{c}\text { Tensile Strength ( Brazilian), } \\
\text { psi }\end{array}$ & 63 & 85 \\
\hline Poisson's Ratio & 0.14 & 0.18 \\
\hline
\end{tabular}

\subsection{Data Acquisition Methods}

The data acquisition system and physical measurement devices are available in the rock/coal cutting laboratory. The system used for this study is shown in the Figure 3.3. Using the facilities, the following parameters were recorded studied in each experiment:

- Cutting pressure

- Penetration Pressure

- Cutting Depth

- Amount of respirable dust generated

- Mass of rock cut product

A model 1246 strip chart recorder is the main part of the data acquisition system with the ARCCS. In edition to the chart recorder, the data obtained from the experiments were also recorded digitally by using the $\mu$ Mac-5000 WOS software. The experiment data on cutting pressure, penetration pressure, and the depth of cut are fed to the strip chart recorder. Research suggests that an attack angle of $45^{\circ}$ (36). So the angle of attack was 
kept at $45^{0}$ for all the experiments. The vertical confinement pressure was kept at approximately 200 psi. The horizontal confinement pressure was about $1 / 3^{\text {rd }}$ of the vertical confinement pressure. The maximum depth of cut was about $1.5 \mathrm{in}$. The advance rate of cutting platform was kept at $0.07 \mathrm{in} / \mathrm{sec}$. A number of experiments were conducted with four different kinds of bits.

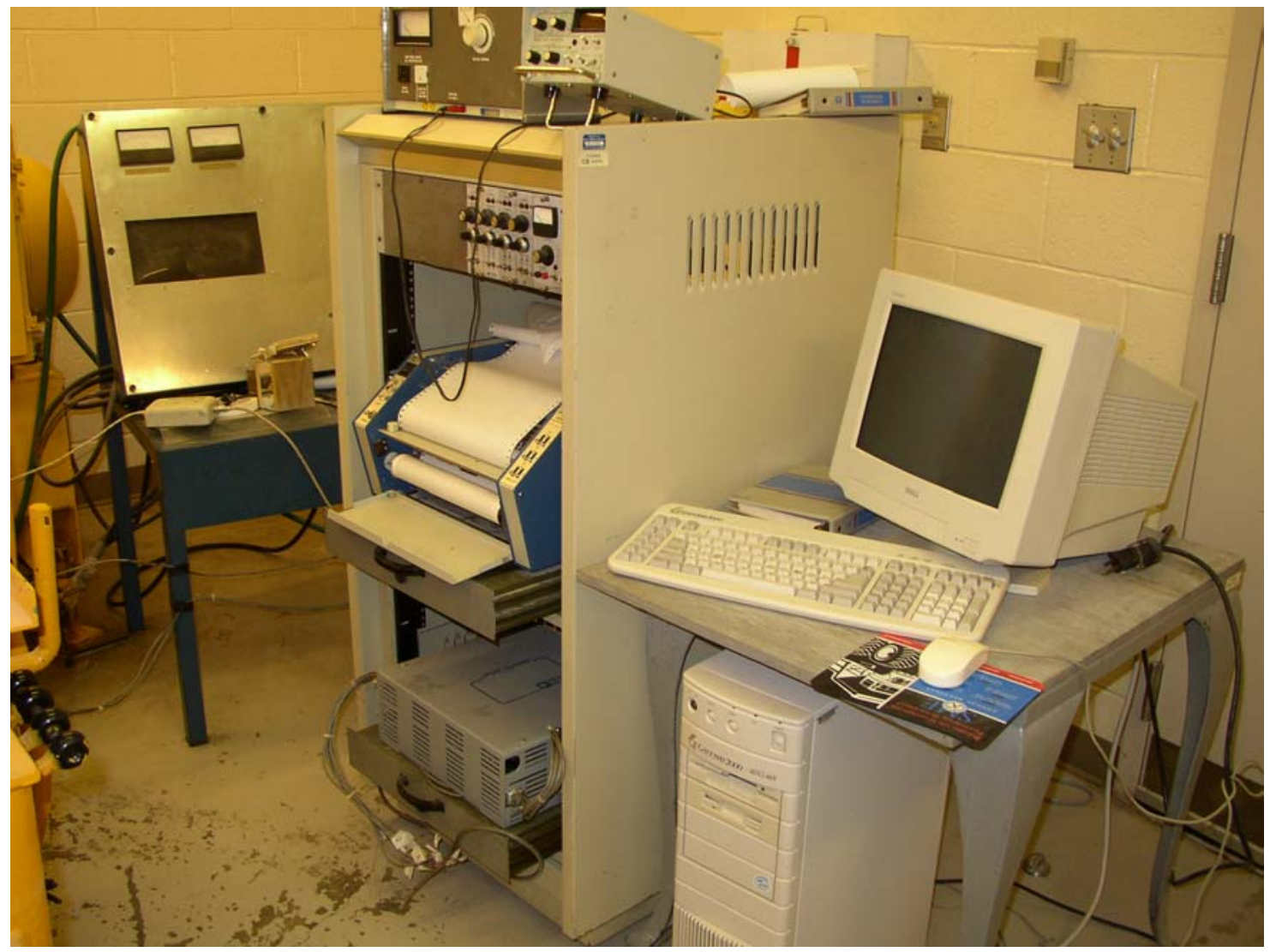

Figure 3.3 . Data Acquisition System of Automated Rotary Cutting Simulator (ARCCS) 


\subsection{Dust sampling}

Series 296 type Marple personal cascade impactors were used to collect the respirable dust (after Anon, 1982). These impactors have six stages and a backup filter. They can give completer, accurate aerodynamic particle size distributions. Two impactors one at the top and one at the bottom with respect to the cutting head, are mounted during every experiment. Dupont air pumps were used to operate the cascade impactors. The air pumps were recharged to full before conducting each experiment. The suction rate of the air pumps was maintained at $2 \mathrm{~L} /$ minute. The principle of operation of the impactors is based on the flow entering the inlet cowl and accelerating through the six radial slots in the first stage. Particle larger than the cut point of the first stage impact on the perforated collection substrate. Then the air stream flows through the narrower slots in the second stage of impactors, smaller particles impact on the substrate in the second stage and so on. The width of the radial slots is constant for each substrate but is smaller for each succeeding stage. The jet velocity is higher for each succeeding, and smaller particles eventually acquire sufficient momentum to impact on one of the stages. The cascade impactors used in this study is shown in the figure 3.4

The six stages of a cascade impactor, stages 3 to 8 collect particles with different Geometric Mean Diameter (GMD) in each stage. Table 3.2 describes the GMD of different stages. The impactors were prepared 24 hours before they were used. The preparation includes the following: cleaning of each stage, cleaning the cowl and evenly spraying the grease to form a film under the slots of the preceding stages. Model C-290MY mylar media filters, $34 \mathrm{~mm}$ in diameter were greased by model 290IGS Impaction 
Grease Sprayer. The original weight of the substrate was measured immediately before and after an experiment to the nearest $0.01 \mathrm{mg}$. by a Sartorious type 2462, semiautomatic, electronic analytical balance with digital readout. The amount of settled dust generated for each experiment was collected in a chamber under the cutting and was weighed subsequently.

Table 3.3. Different stages and their GMD in a cascade impactor

\begin{tabular}{|c|c|c|c|c|c|}
\hline Stage & Stage 3 & Stage 4 & Stage 5 & Stage 6 & Stage 7 \\
\hline GMD microns & 12.25 & 7.75 & 4.58 & 2.65 & 1.34 \\
\hline
\end{tabular}

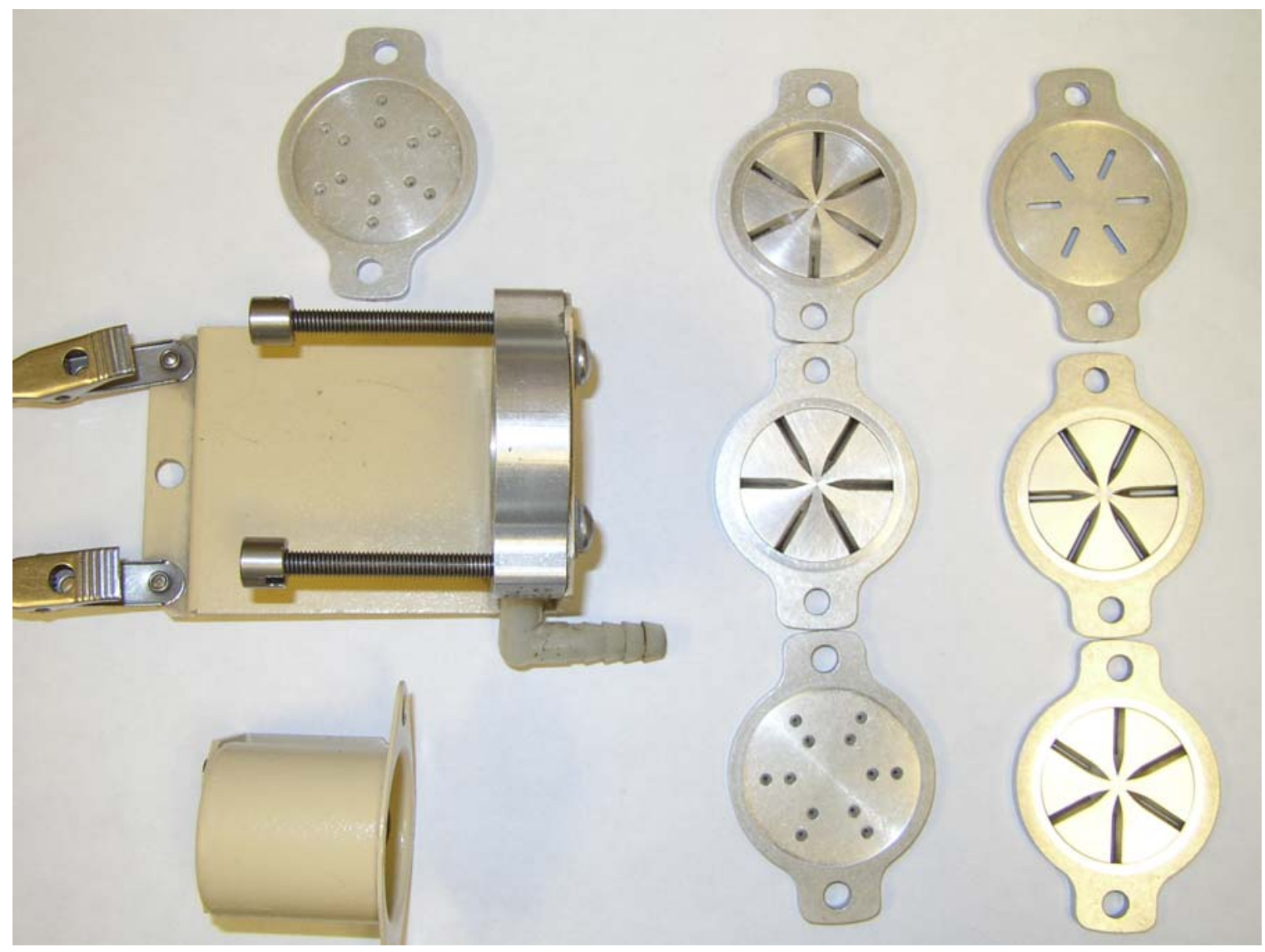

Figure 3.4. Cascade Impactor assembly 


\subsection{Characteristics of Cutting Bits}

Five kind of conical bits were tested. These bits are U76K, bit A, bit B, bit C, bit D and all of these conical bits were designed by Khair (2001) and fabricated by Kennametal Inc of Bedford, Pennsylvania. The geometry of all the bits from bit A through Bit D is same except for the size and shape of the of the tip. Bit A has the largest size tip, bit B has the medium size tip, bit $\mathrm{C}$ has the smallest size tip, whereas bit $\mathrm{D}$ has groves cut in the tip to give more stress concentration around the tip. All of these bits are typically made of 15B35 steel and are simultaneously brazed and heat-treated. The tips are composed of tungsten carbide. The insert has an average density of $14.6 \mathrm{~g} / \mathrm{cm}^{3}$, contains $8.2-8.8 \%$ cobalt. The bits used are shown in the figures 3.5-3.10. Bits A through D are compared with bit U76k that is also obtained from Kennametal. In the previous research, U76K was among the best bits in regards to the energy consumption $(25,28)$. 


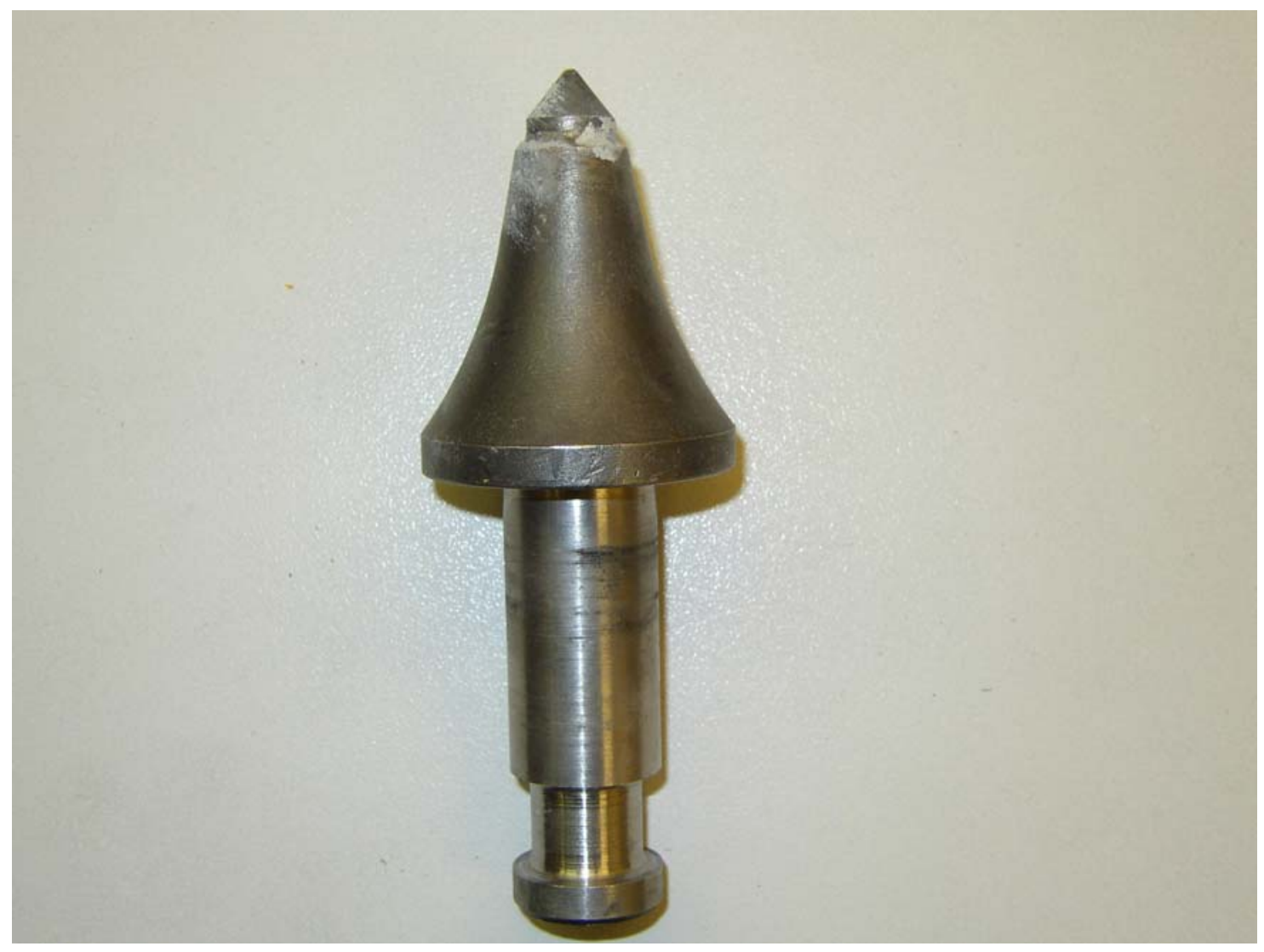

Figure 3.5. Bit A (Bit with the largest tip) 


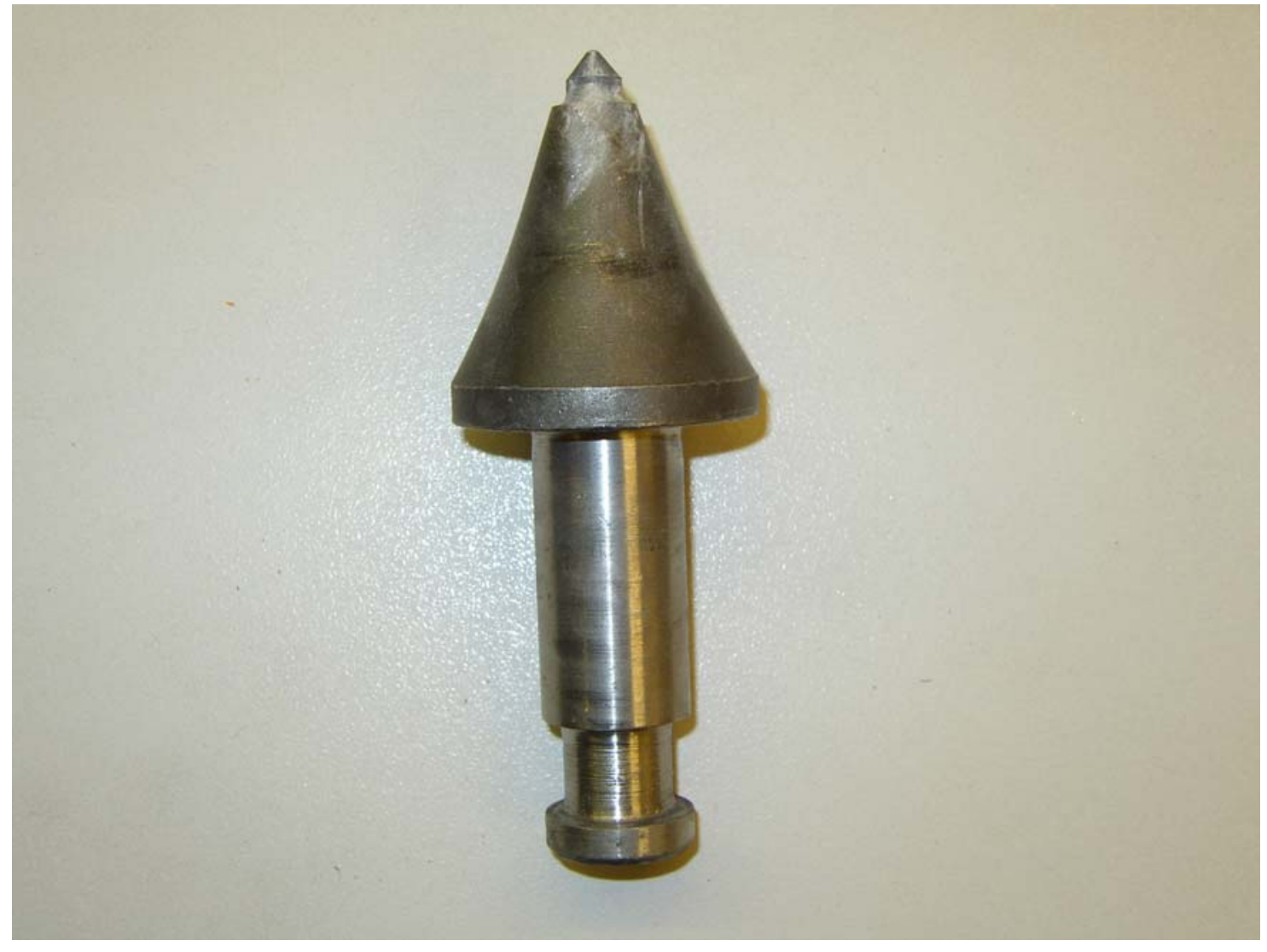

Figure 3.6. Bit B (Bit with medium size tip) 


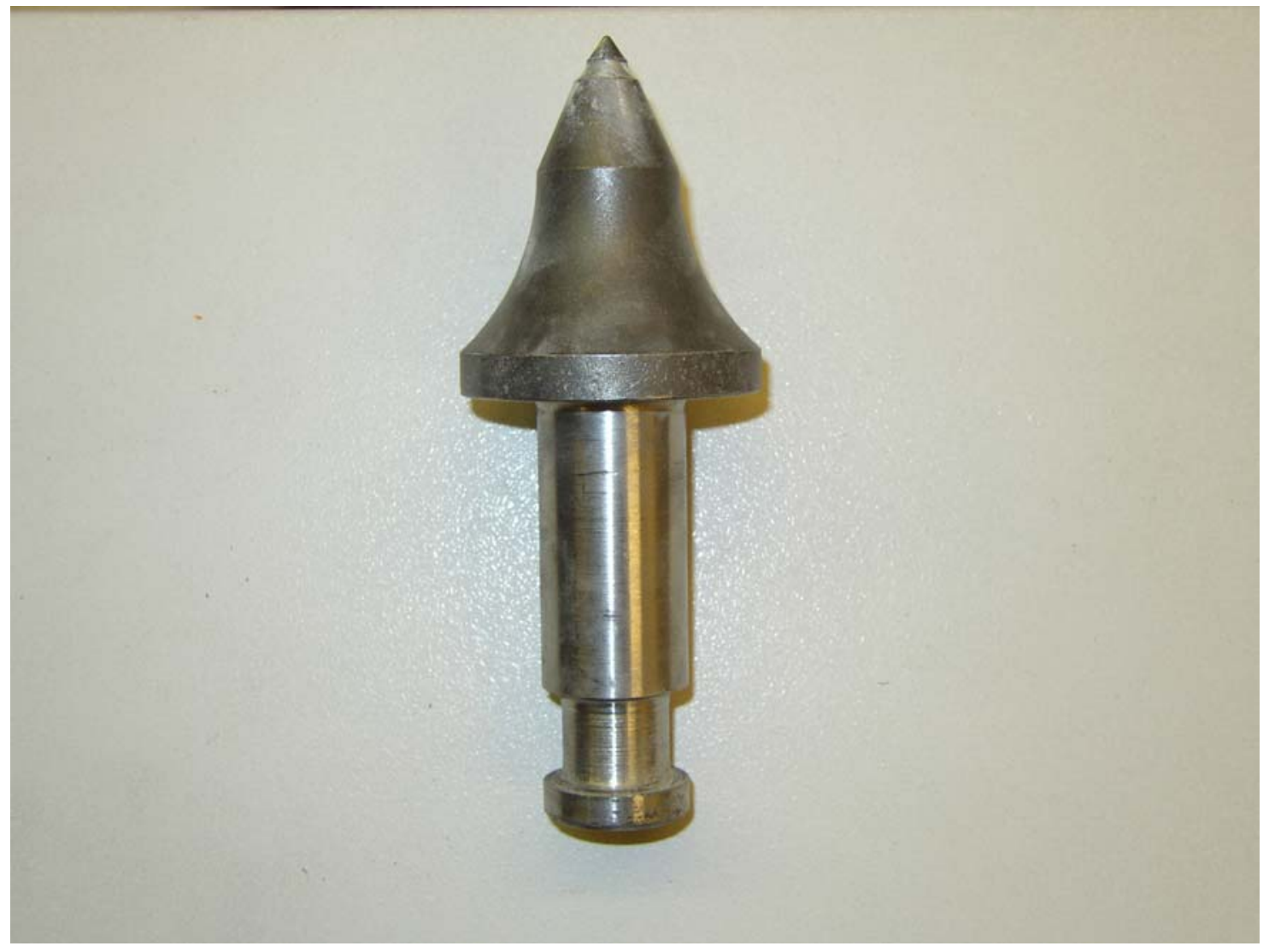

Figure 3.7 . Bit C (bit with small size tip) 


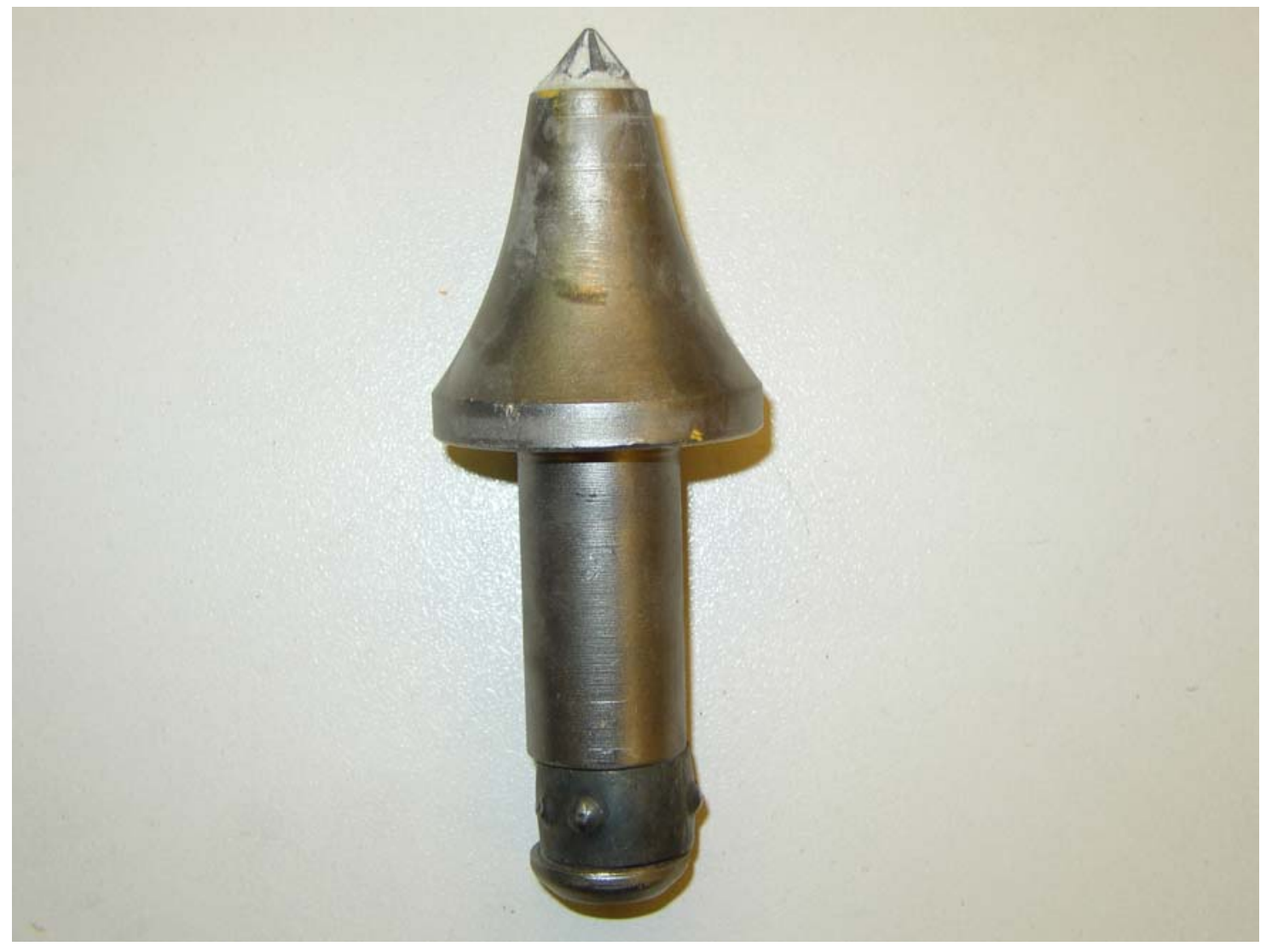

Figure 3.8 . Bit D (Bit with ridges/groves on the tip) 


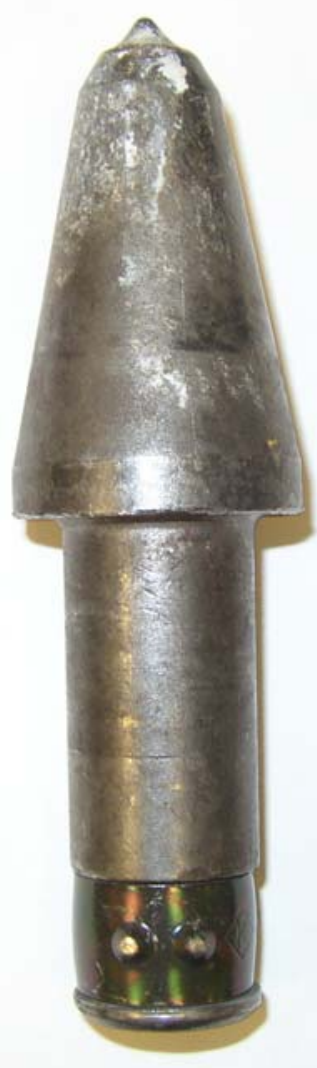

Figure 3.9. Bit U76K 


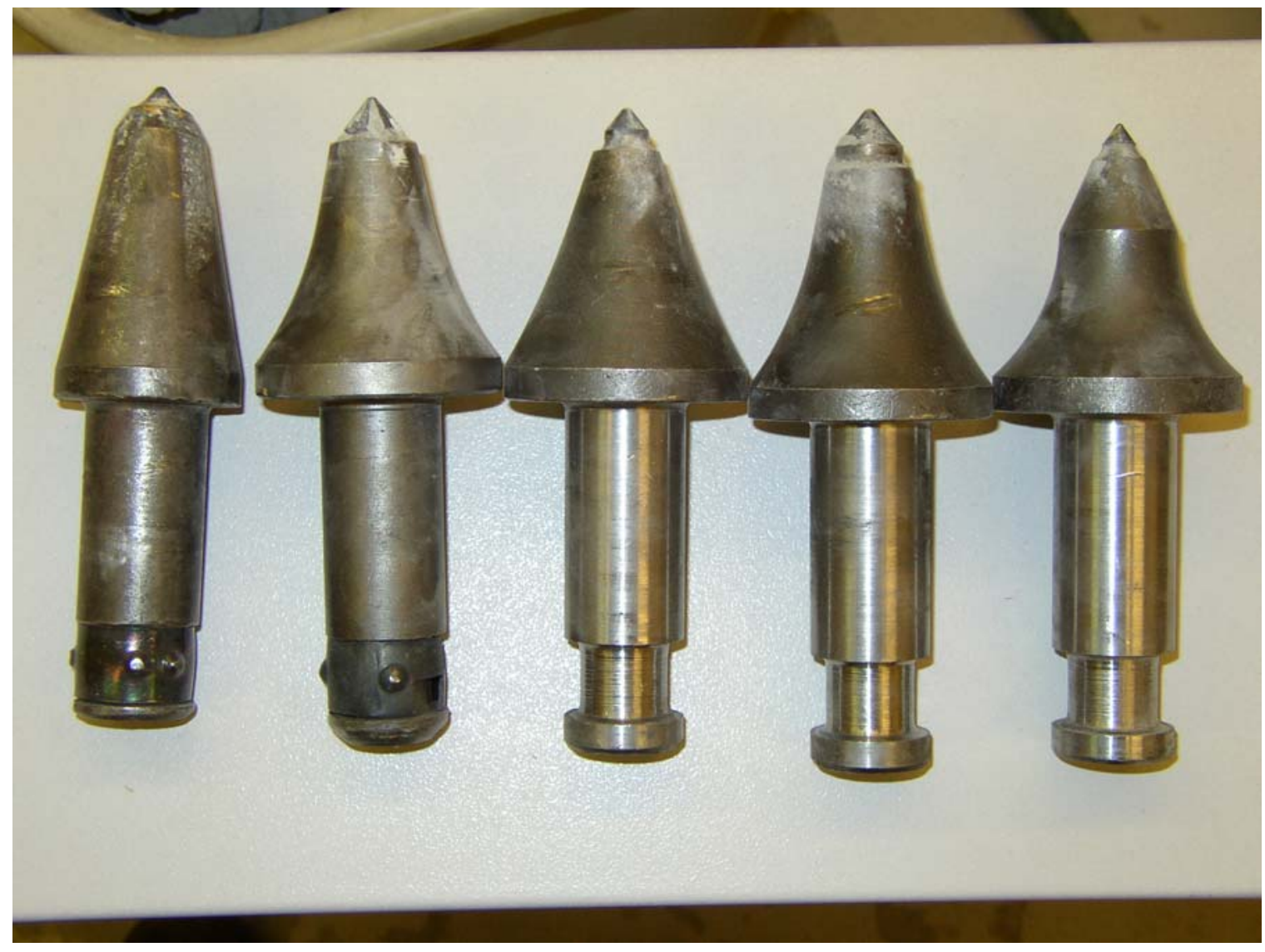

Figure 3.10. All bits used in this study compared 


\subsection{Rock Cutting Experiments}

Molded specimens were placed in the confining chamber of the ARCCS. A thick steel plate and wooden plates were placed between specimen and hydraulic jacks to distribute the confining pressure all over the specimen surfaces. The operating parameters such as velocity of the cutting head (rpm), and the maximum depth of cut were set prior to starting the experiment. The velocity of the cutting head was set at $100 \mathrm{rpm}$ and the maximum dept of cut for all the experiment was set at 1.5 inches. The cutting drum of the ARCCS can hold nine bits at a time; the bit spacing allowed by the design of the drum is 1.5 inches from tip to tip. The average rate of advance of the cutting drum for each experiment was found to be $0.14 \mathrm{in} / \mathrm{sec}$. Four different kinds of bits were mounted in the bit holders for each experiment. For each experiment, the depth of cut was predetermined and cutting head stopped advancing automatically when predetermined depth of cut was reached. Two cascade impactors were placed, one at the bottom and one at the middle horizon of the cutting head to take the dust samples as shown in the Figure 3.4 and mentioned earlier. 


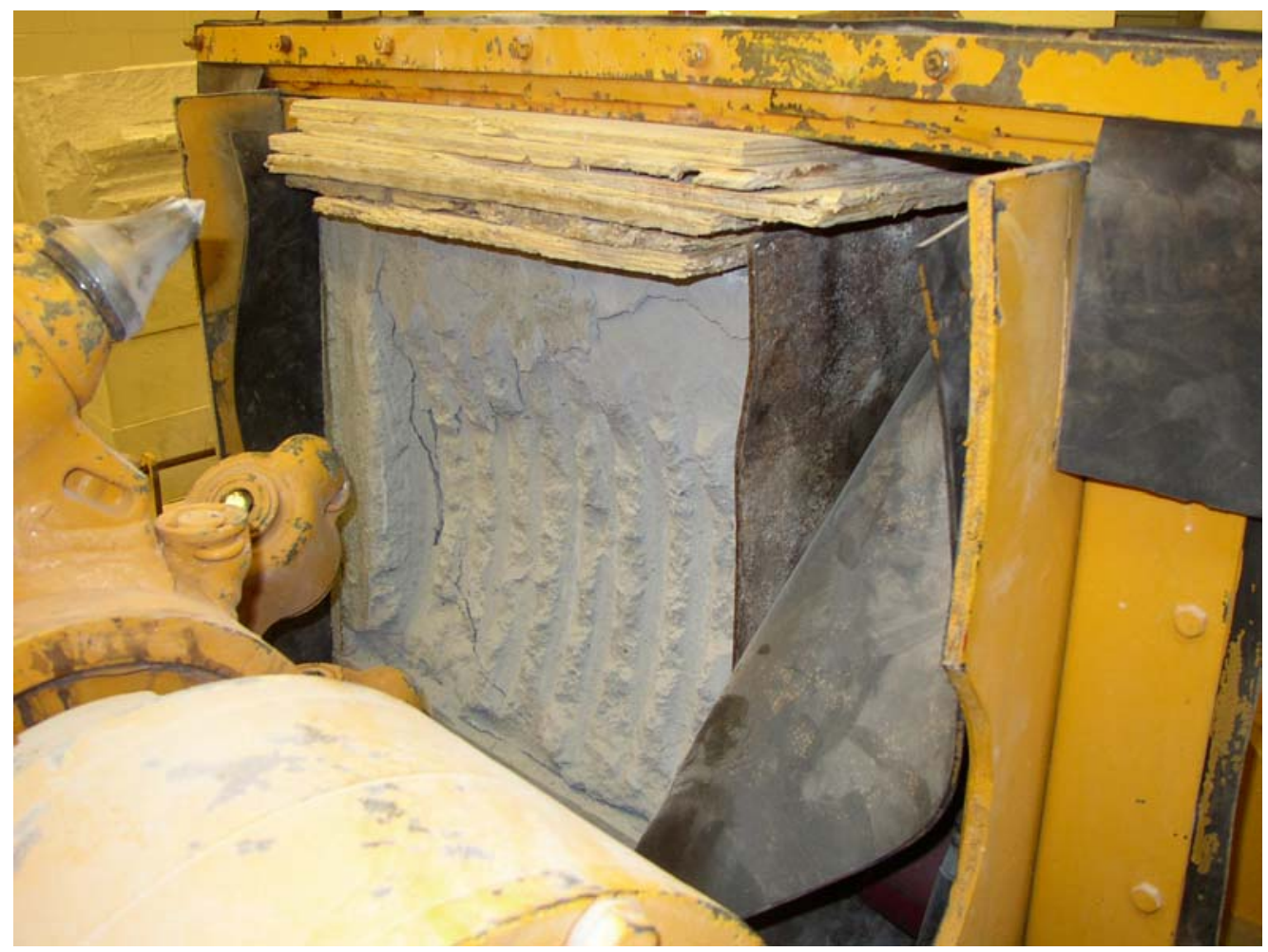

\section{Figure 3.11 . Experimental Setup}

The Experiments were run with all the 9 bits placed in the cutting drum of the ARCCS for all 4 kinds of bits in each experiment. The drum ceases to advance when it reaches the predetermined depth of cut due to the automatic stopping feature of the ARCCS. In the mean time the cutting parameters; cutting pressure and penetration force and depth of cut were recorded by the computer and the analog chart data recorder at the same time. The ARCCS was stopped after the experiment and the dust generated was allowed to settle down while the air pumps were still run to collect the respirable dust. Amount of cut material and the amount of respirable during each experiment was weighed and the subsequent specific dust was measured. The specimen after cutting are shown in the Figures 3.12-3.14 


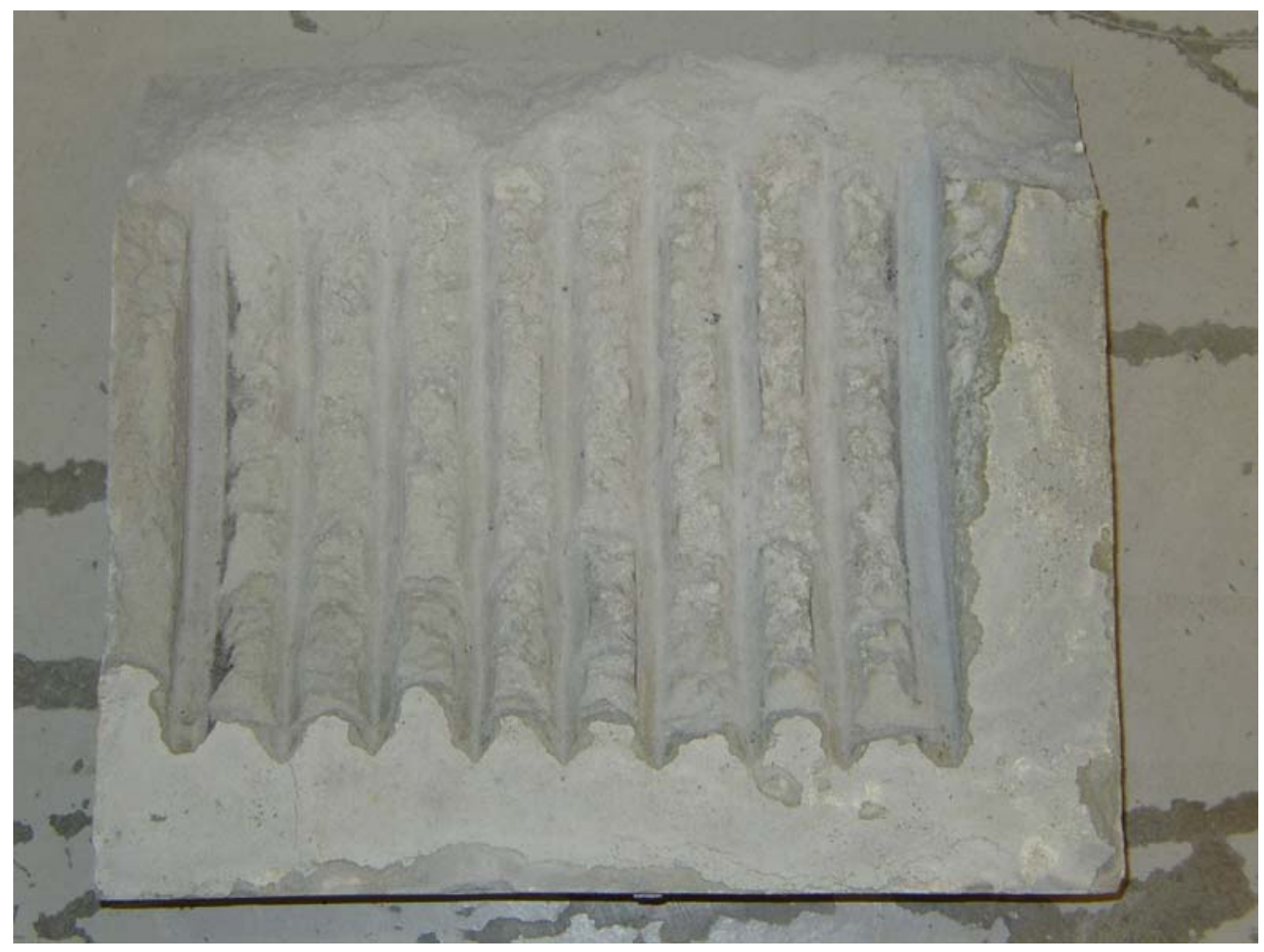

Figure 3.12 . Multiple Cutting in the specimen block (Bit C) 


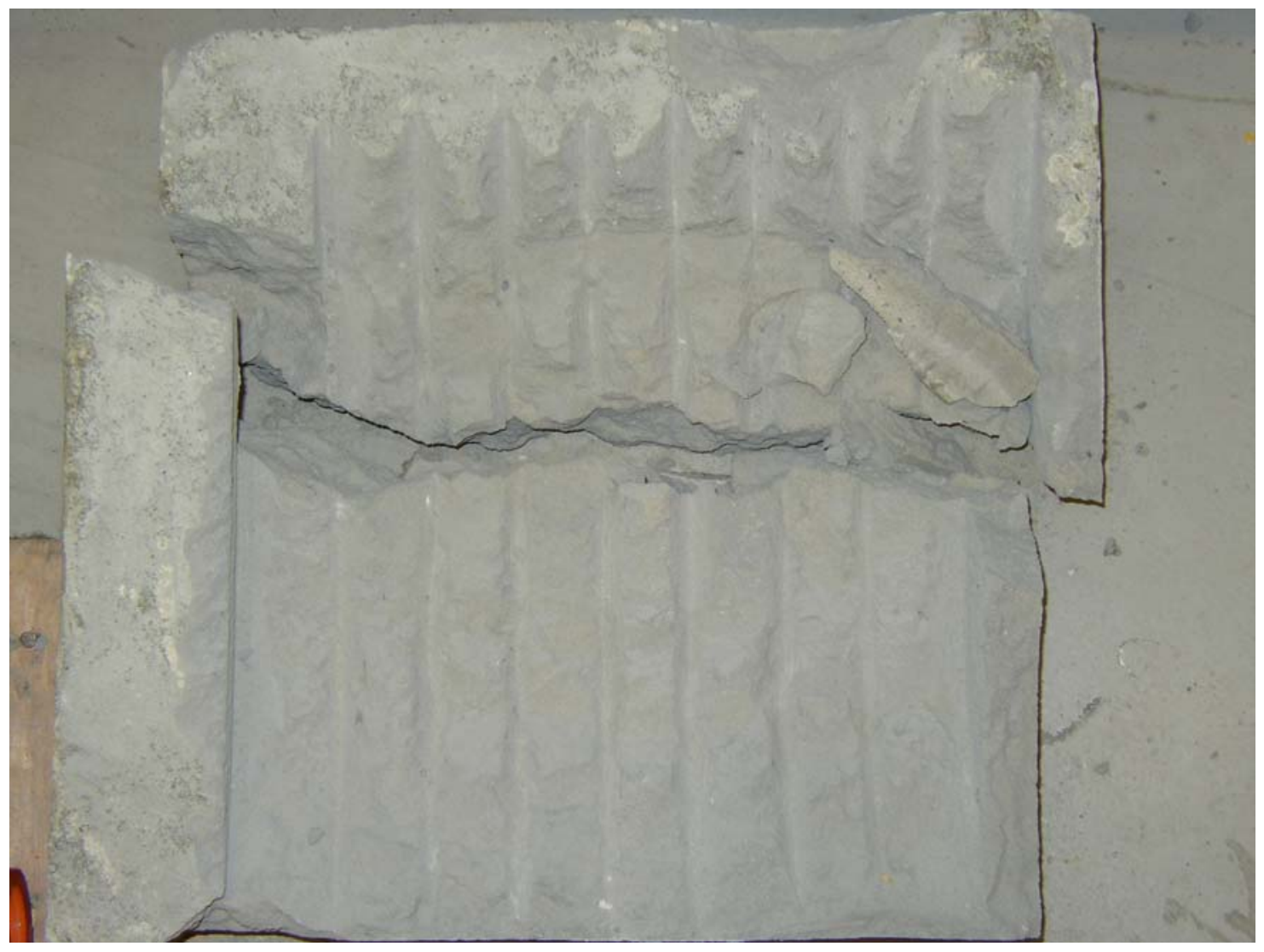

Figure 3.13 . Multiple Cutting in the specimen block (bit B) 


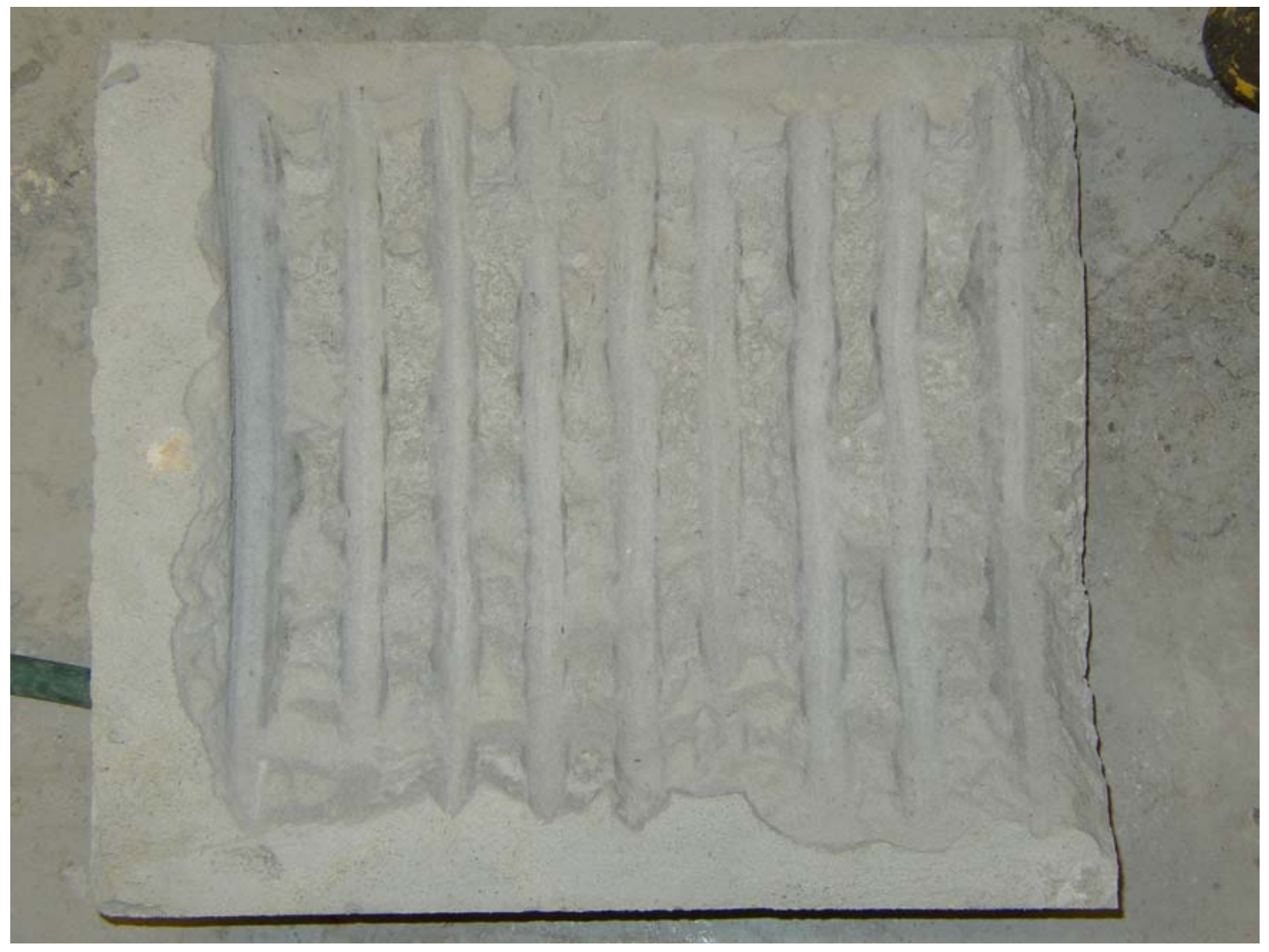

Figure 3.14 . Multiple Cutting in the specimen block (Big A) 


\section{Chapter 4}

\section{Experimental Results and Analysis}

Although a limited number of experiments were carried out, some interesting results have been obtained from this research. According to the experimental design, five concrete blocks were used as described earlier. Five types of bits including U76K and four newly designed bits (bits A, B, C \& D) were used to cut each block. A total of five experiments were carried out using one type of bit at a time in each of the nine bit holders of the drum. The cutting and penetration force required, penetration depth, the amount of respirable dust and cut products were recorded. The resultant force, specific energy consumed and the specific dust produced for each experiments were calculated and shown in the Figures 4.1- 4.18. In each experiment the respirable dust generated is collected at two locations in the ARCCS one at the middle of the drum and another at the bottom of the drum area.

\subsection{Results and Analysis}

The maximum depth of cut/sumping was set mechanically to 1.5-1.6 inches before the bit cone base will interact with the rock, however some bit penetrated only to a limited depth and in some experiments the bit cleared the path beyond 1.5 inches and after that the machine stalled. In this case the required forces by some bits were less beyond the 1.5 inches depth of cut. The variations in the parameters recorded for each bit and experiments are attributed to the difference in bit geometry and shape. A close analysis of the results show (Figures4.1 - 4.20), that the relative position of the tip in regard to the 
bit body and size of the bit tip and cone tip have a detrimental effect on the performance of the individual bits.

\subsection{Bit Geometry and Penetration Force}

It is obvious from the graph that penetration force increases with the increasing size of the bit tip for bits A through D. The bit U76K has the largest penetration force. (Fig. 4.13 $\& 4.16)$

\subsection{Bit Geometry and Cutting Force}

The results of the experiment showed that the cutting force decreases with the decrease in the size of the bit tip. Bit A has the largest cutting force and bit U76k has the smallest cutting force. ( Fig. 4.2, 4.14, 4.17)

\subsection{Resultant Forces}

The important characteristics of the bit design is to consume less energy during penetration and to maximize cutting force, limiting penetration minimizes cutting products. Bit U76K consumed more than 3 times penetration forces than the rest of the bits while its cutting force is less than the others. However the resultant force for U76K is higher than the rest of the bits (Fig. 4.18), this resulted in higher specific dust and higher specific energy, an indication of the dissipating energy in grinding of the face. The resultant force consumed by the bit should be compared with specific dust generation and specific energy. Hence specific dust and specific energy should be a measure of the optimum bit parameter design. 


\subsection{Bit Geometry and Specific Dust}

The results of the experiment showed that the specific dust generated increases from Bit A through bit D and U76K (fig 4.19). It is obvious that amount of dust generation is proportional to the area of contact, interface between the bit tip and the rock. At the beginning of the cut, limited penetration has advantages for U76K, because of the small bit tip. However after the depth of cut exceeds the height of the bit tip the body/cone of the bit, which is much larger than the bit tip, will have contact with the rock and results in jamming of the bit with the face. Bit D has the same bit cone geometry as bit A, however the size of the bit tip is smaller and the bit height is shorter. Further more the bit tip has ridges. During cutting process forces required by the Bit D were much less than bit A, because of higher stress concentration developed on the rock by these ridges. However beyond the height of the bit tip, the rock grove was not cleared by the bit tip, hence the bit came in contact with the rock. It is evident that the stream lining of the bit tip and bit cone is essential in order to consume less forces and produce less dust during cutting process.

\subsection{Bit Geometry and Specific Energy}

The experimental results show that the amount of the specific energy required increases from Bit A through Bit D, with bit U76K being the largest consumer of the specific energy, as shown in the Figure (4.20). Observation of the experiment and analysis of data indicated that two major parameters effecting performance of the cutting tool; 1) stream lining of the bit tip and bit cone, 2) the size of the bit tip. The stream lining of the bit 
geometry and cylindrical bit cone not only require less cutting forces but it will also reduce dust generation, limiting cutting and abrasion of the rock by the bit cone. The size of the bit tip induces higher fracture intensity on rock underneath the bit, hence in a subsequent cut a larger amount of material is removed with less required forces. Hence reduces specific energy by doing so. 
Penetration force Vs depth of cut (Bit A)

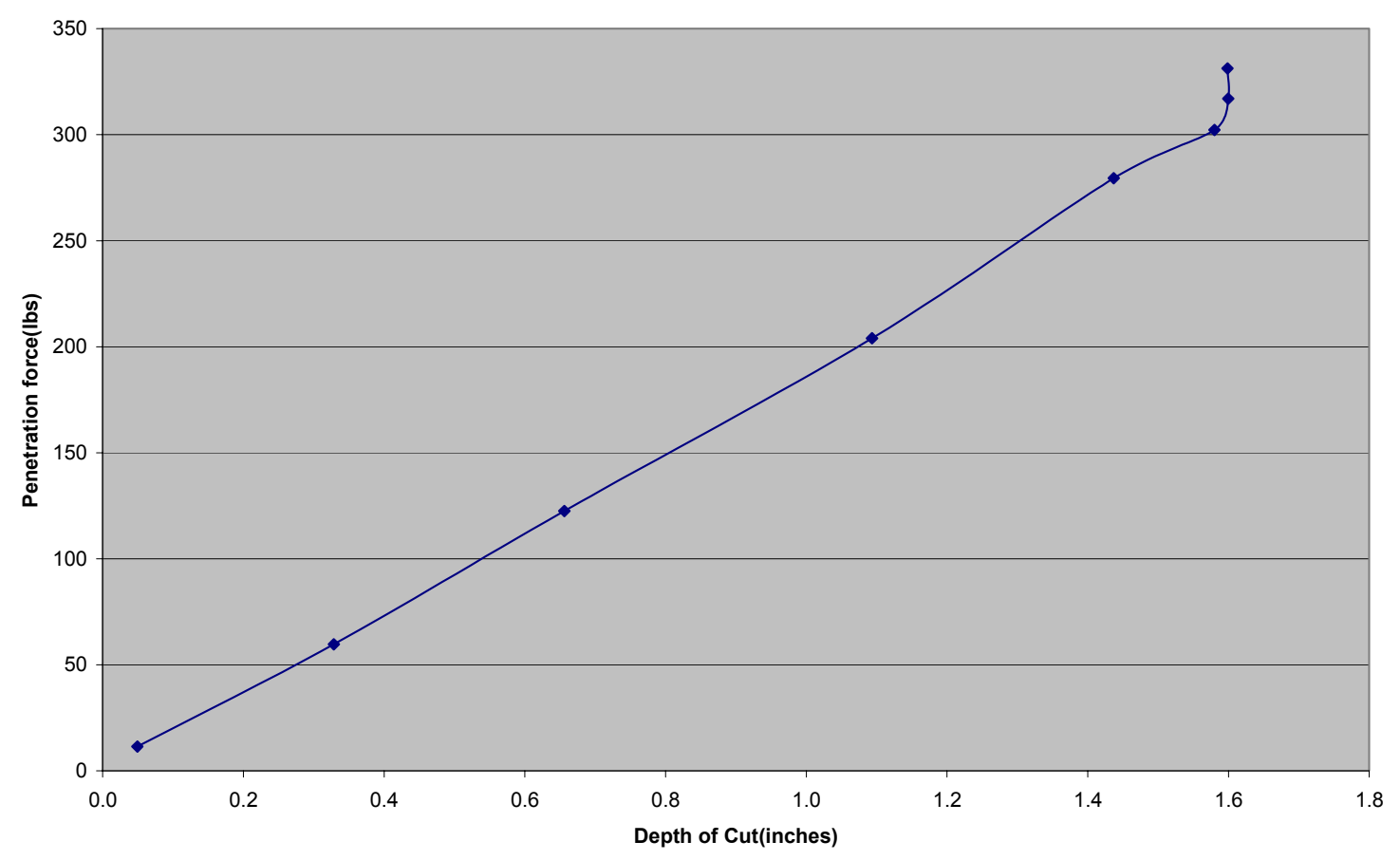

Fig 4.1 Graph showing penetration force for bit $\mathrm{A}$ 
Cutting Force Vs Depth of Cut (Bit A)

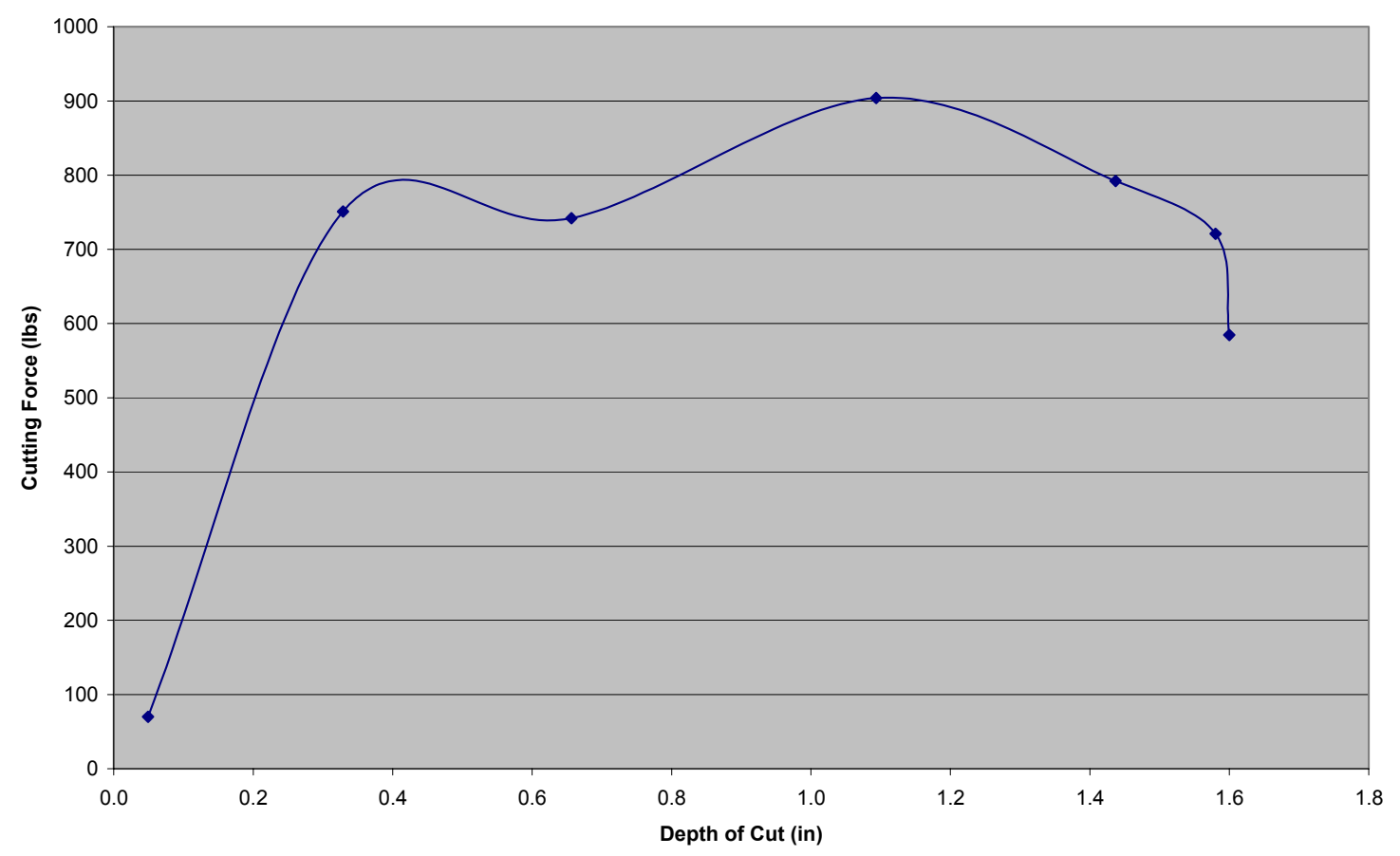

Fig 4.2 Graph showing cutting force for bit $\mathrm{A}$ 
Resultant Force Vs Depth of cut for bit(A)

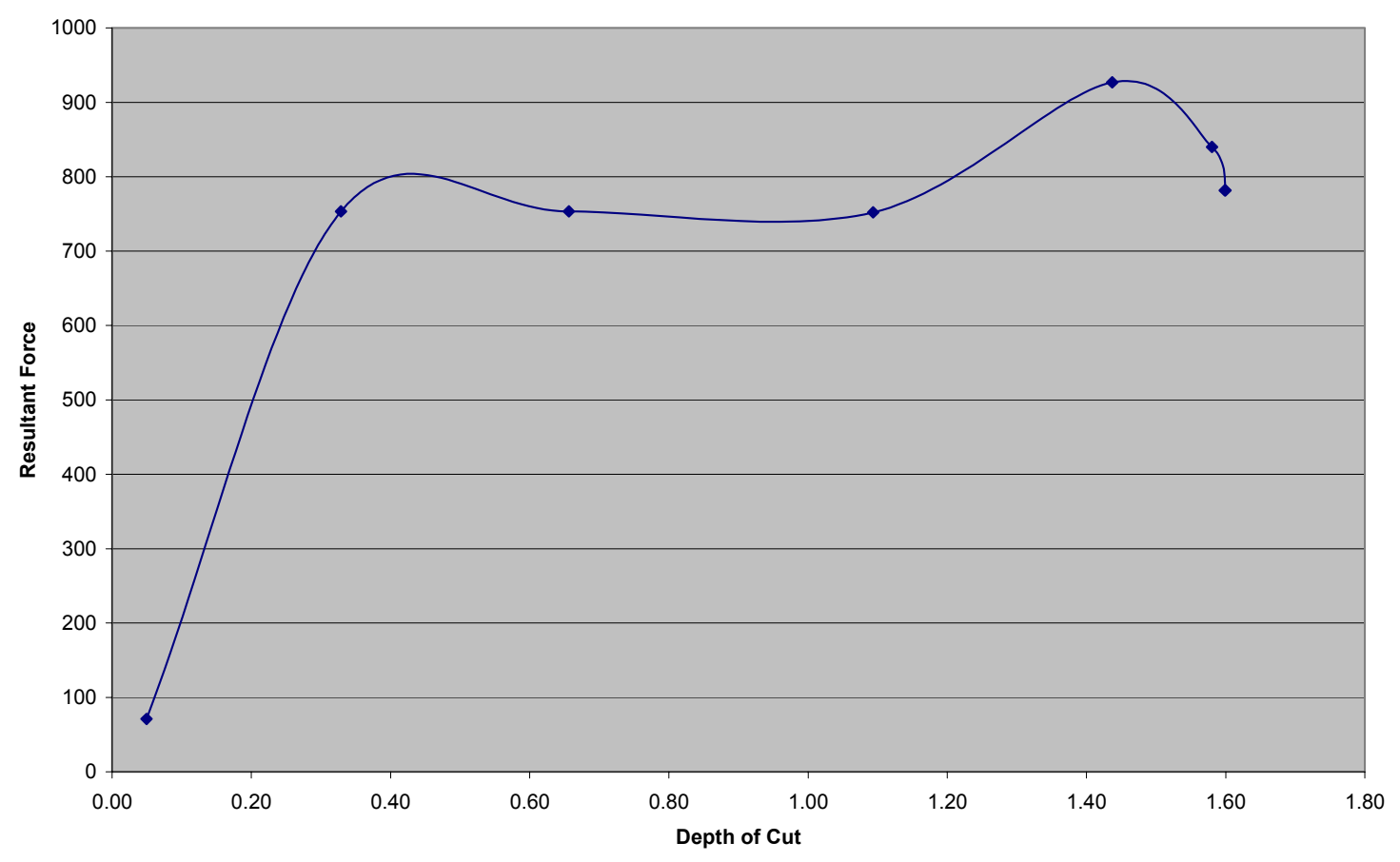

Fig 4.3 Graph showing resultant force for bit $\mathrm{A}$ 
Penetration Force Vs Depth of Cut (Bit B)

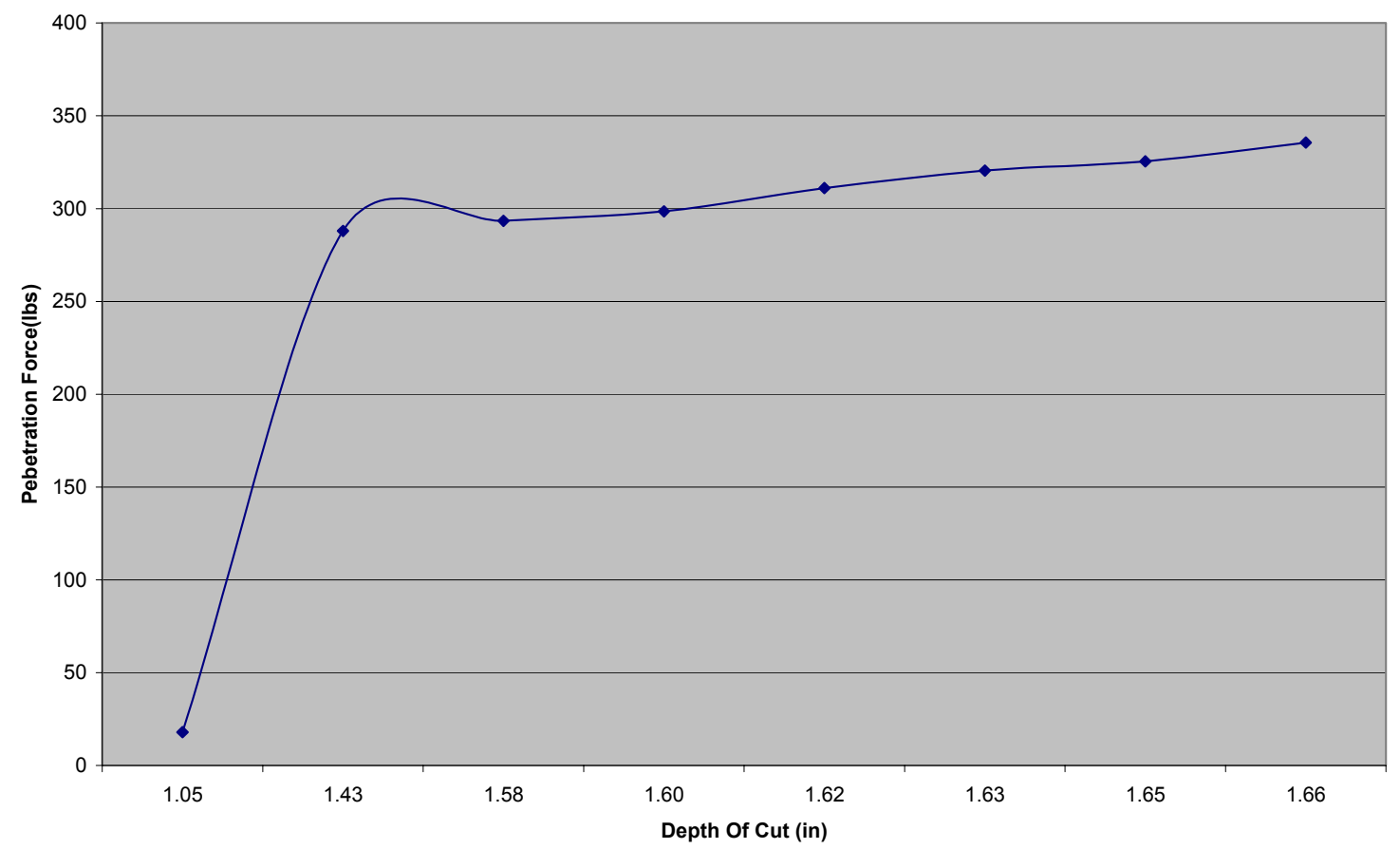

Fig 4.4 Graph showing penetration force for bit B 
Cutting Force Vs Depth of Cut (Bit B)

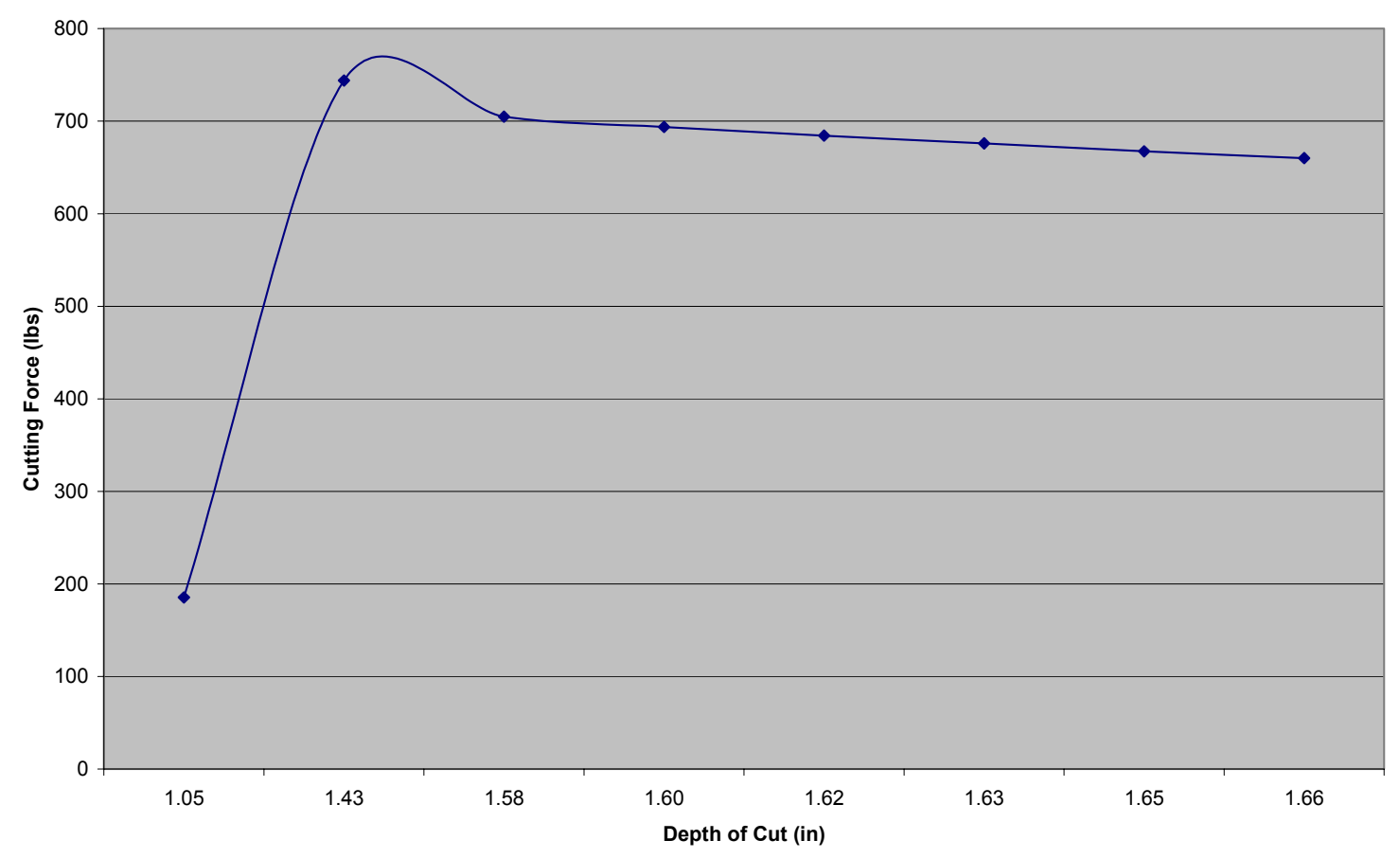

Fig 4.5 Graph showing cutting force for bit B 
Resultant Force Vs Depth of Cut (B)

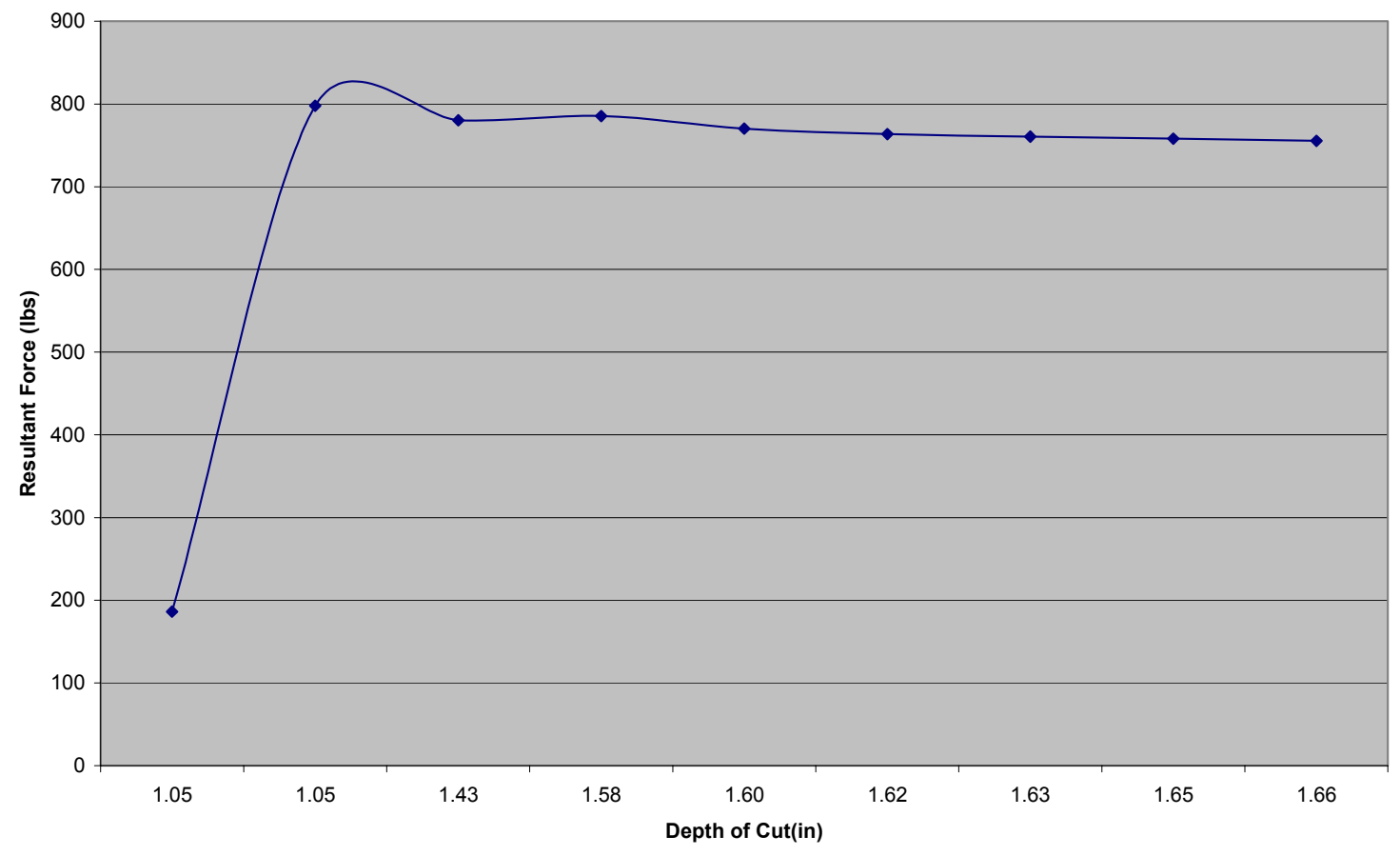

Fig 4.6 Graph showing resultant force for bit B 
Penetration Force Vs Depth of Cut (Bit C)

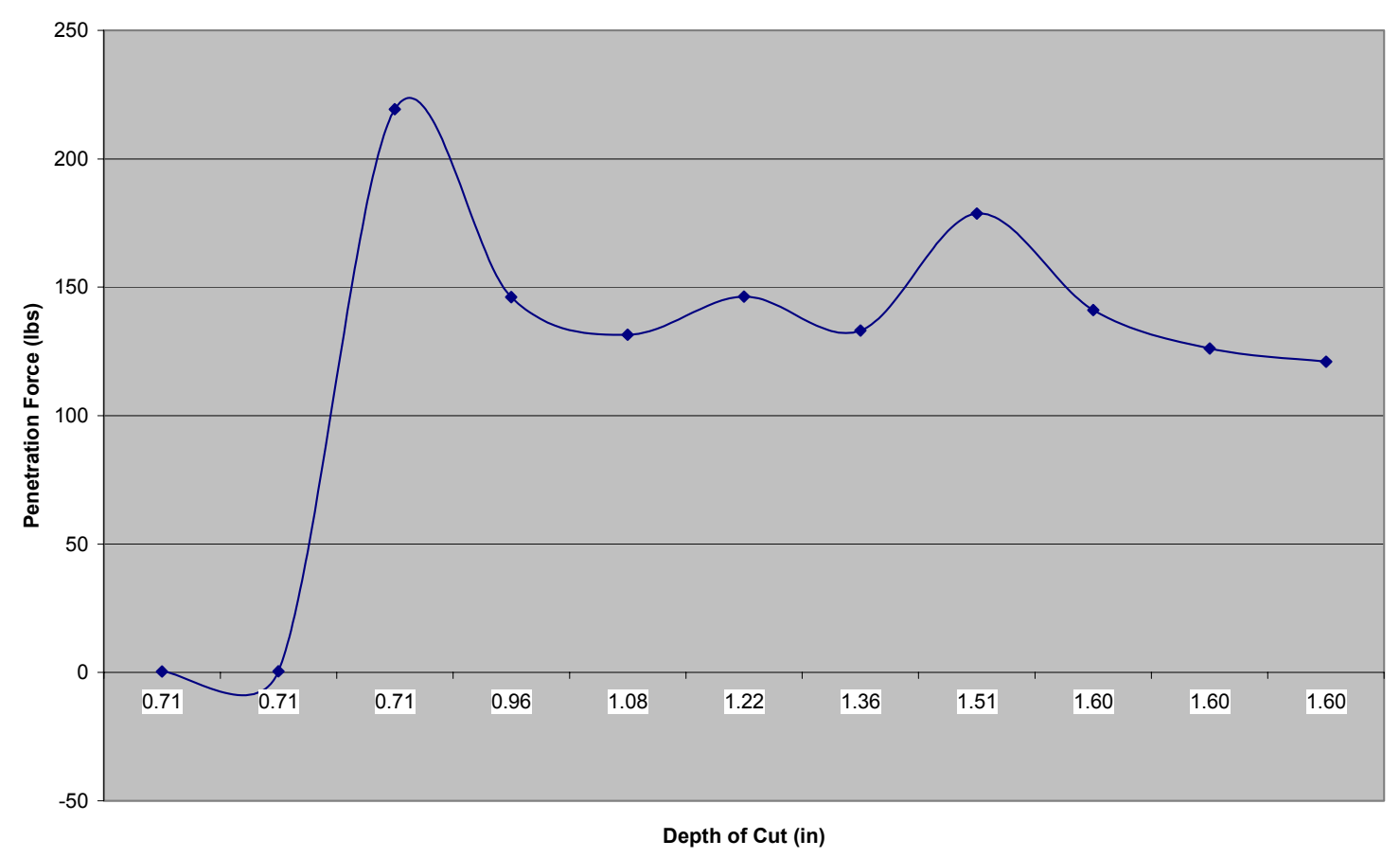

Fig 4.7 Graph showing penetration force for bit $\mathrm{C}$ 
Cutting Force Vs Depth of Cut (Bit C)

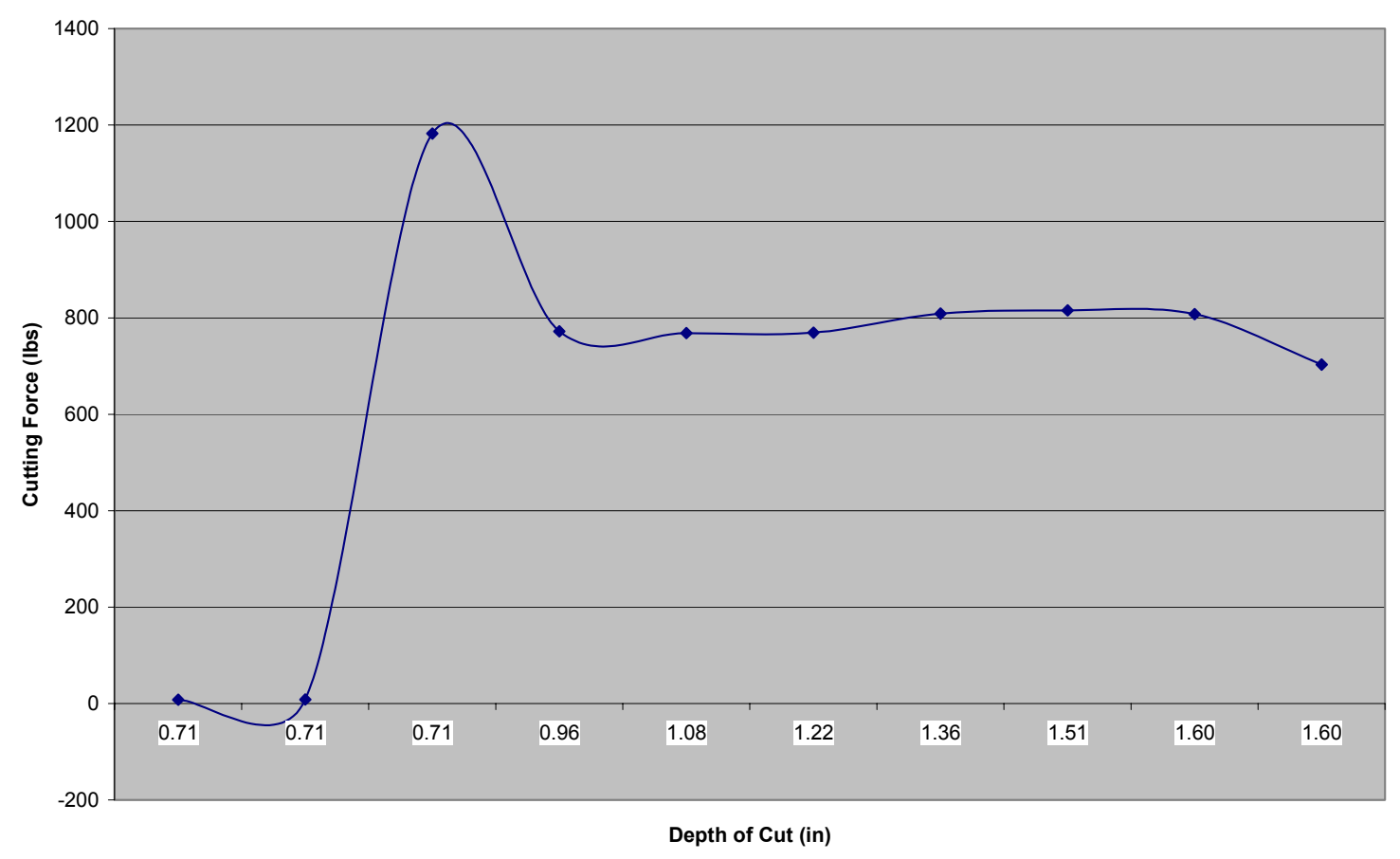

Fig 4.8 Graph showing cutting force for bit $\mathrm{C}$ 
Resultant Force Vs Depth of Cut (C)

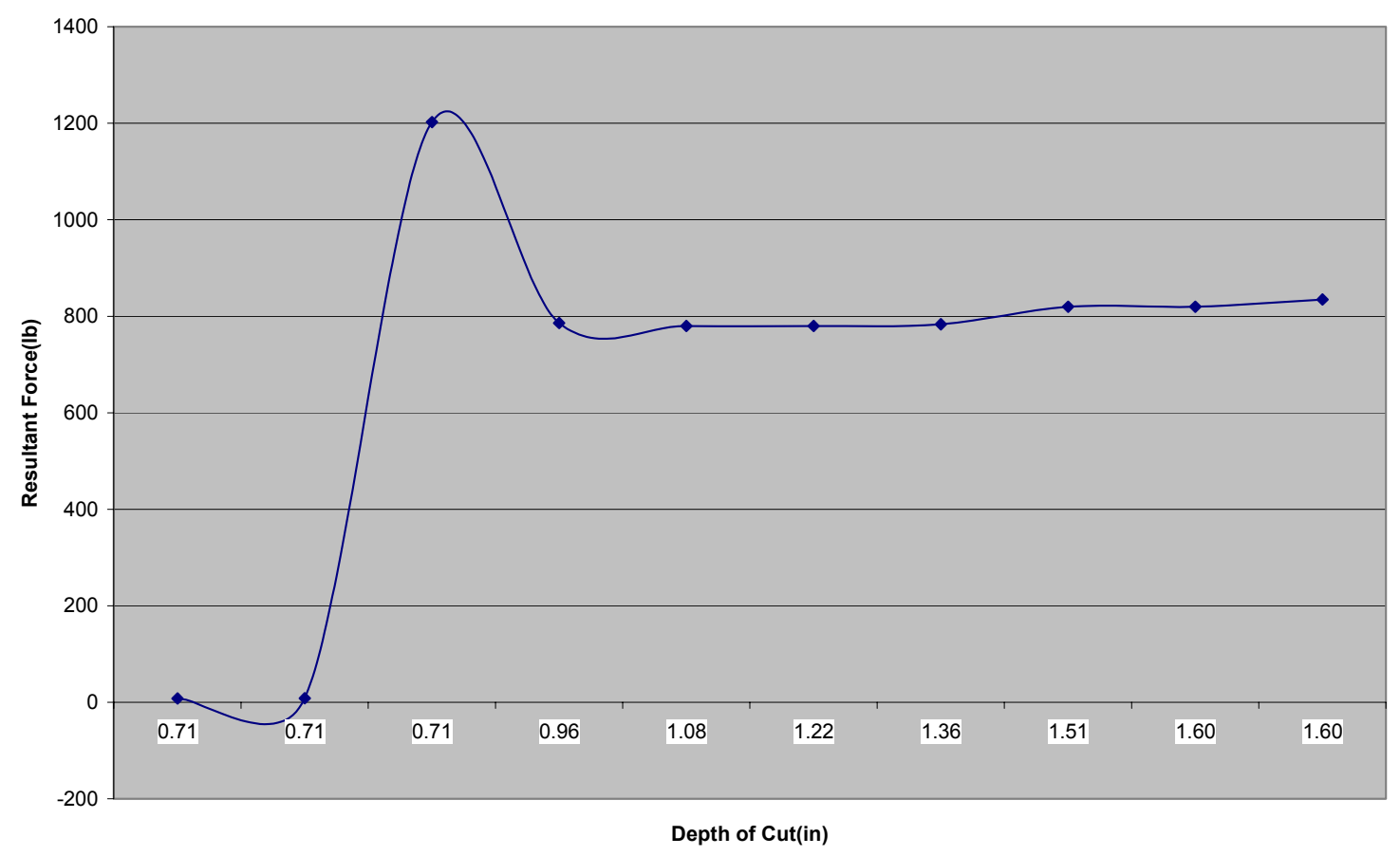

Fig 4.9 Graph showing resultant force for bit C 
Penetration Force Vs Depth of Cut (Bit D)

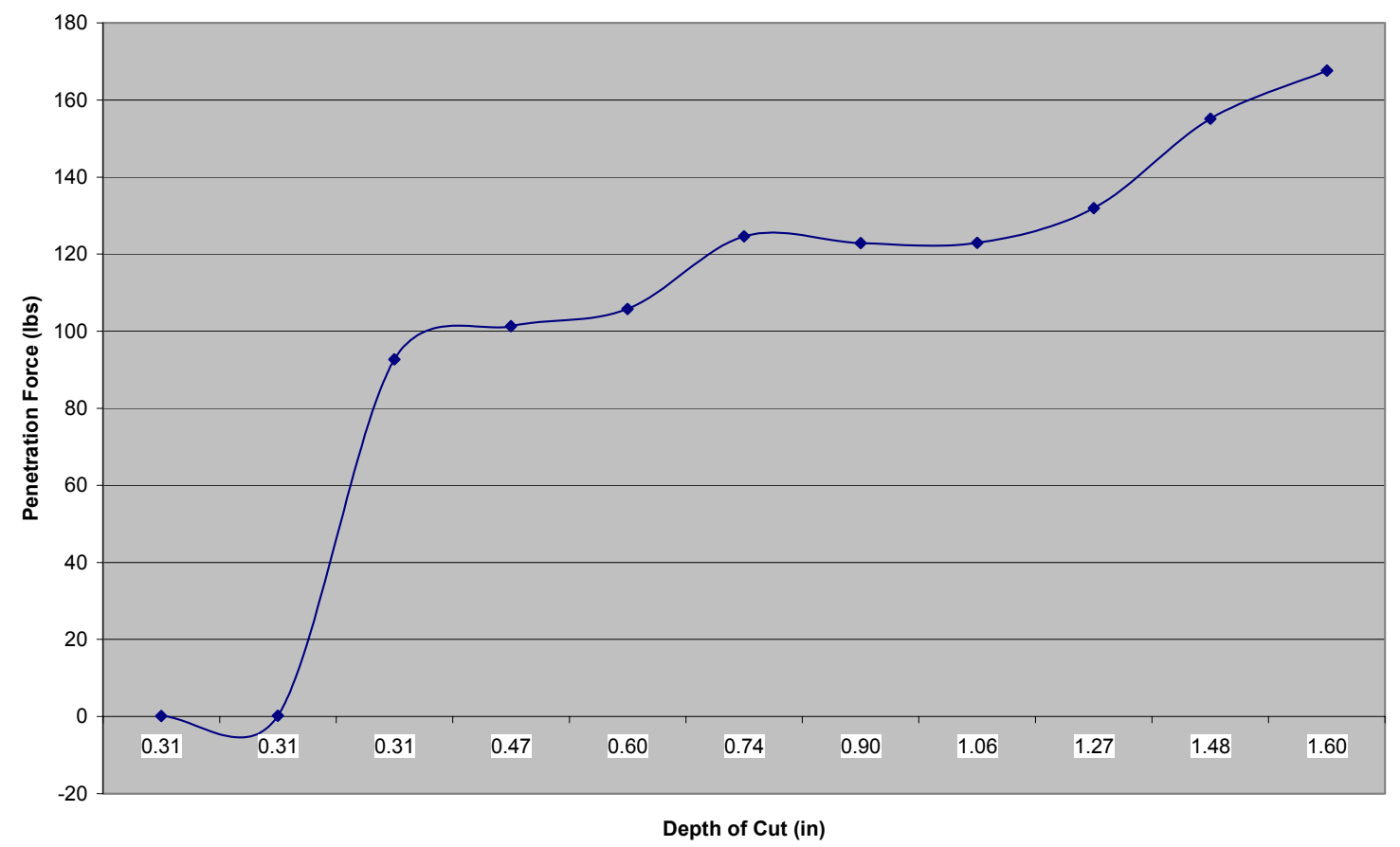

Fig 4.10 graph showing penetration force for bit D 
Cutting Force Vs Depth of Cut (Bit D)

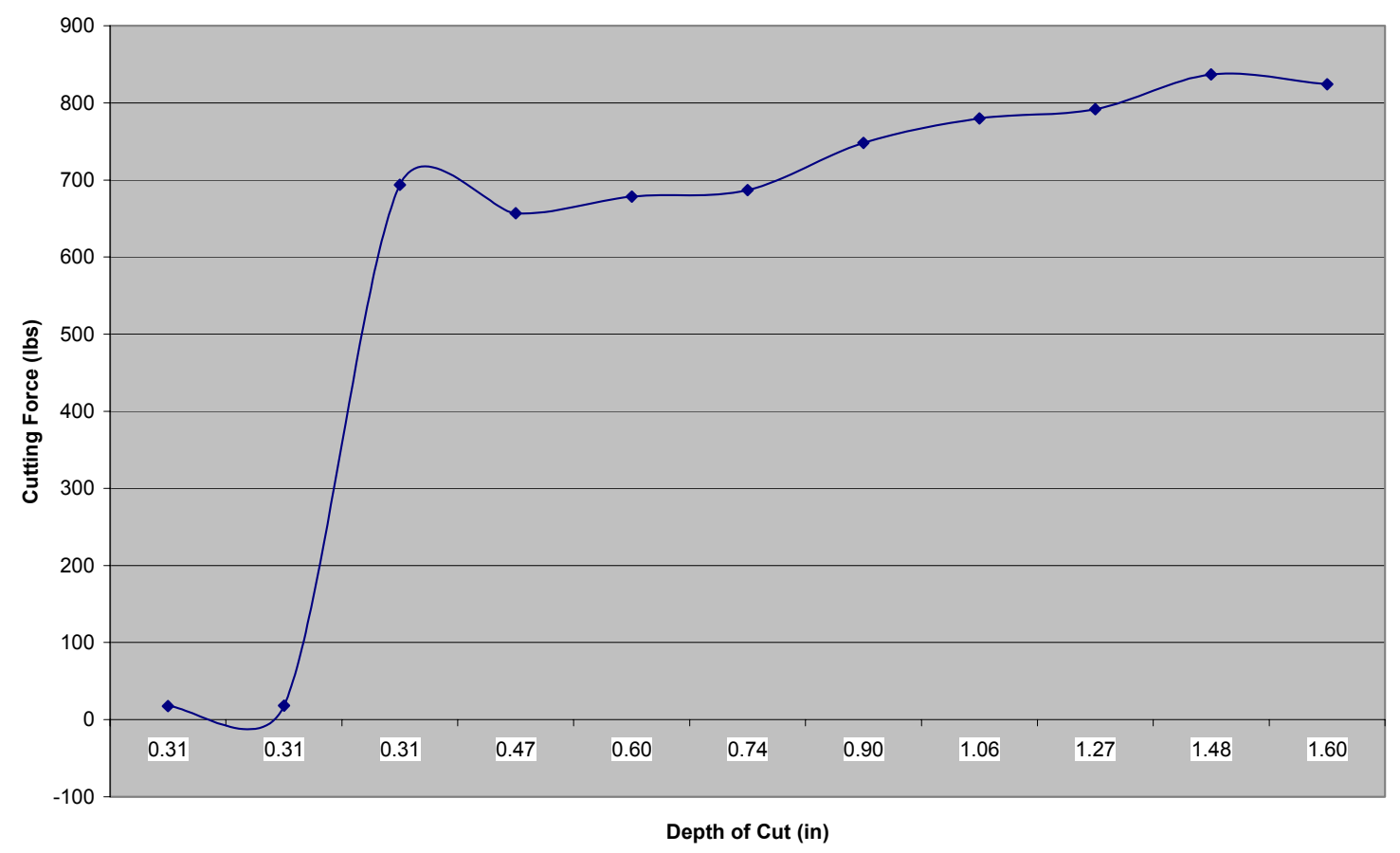

Fig 4.11 Graph showing cutting force for bit D 
Resultant Force Vs Depth of Cut bit(D)

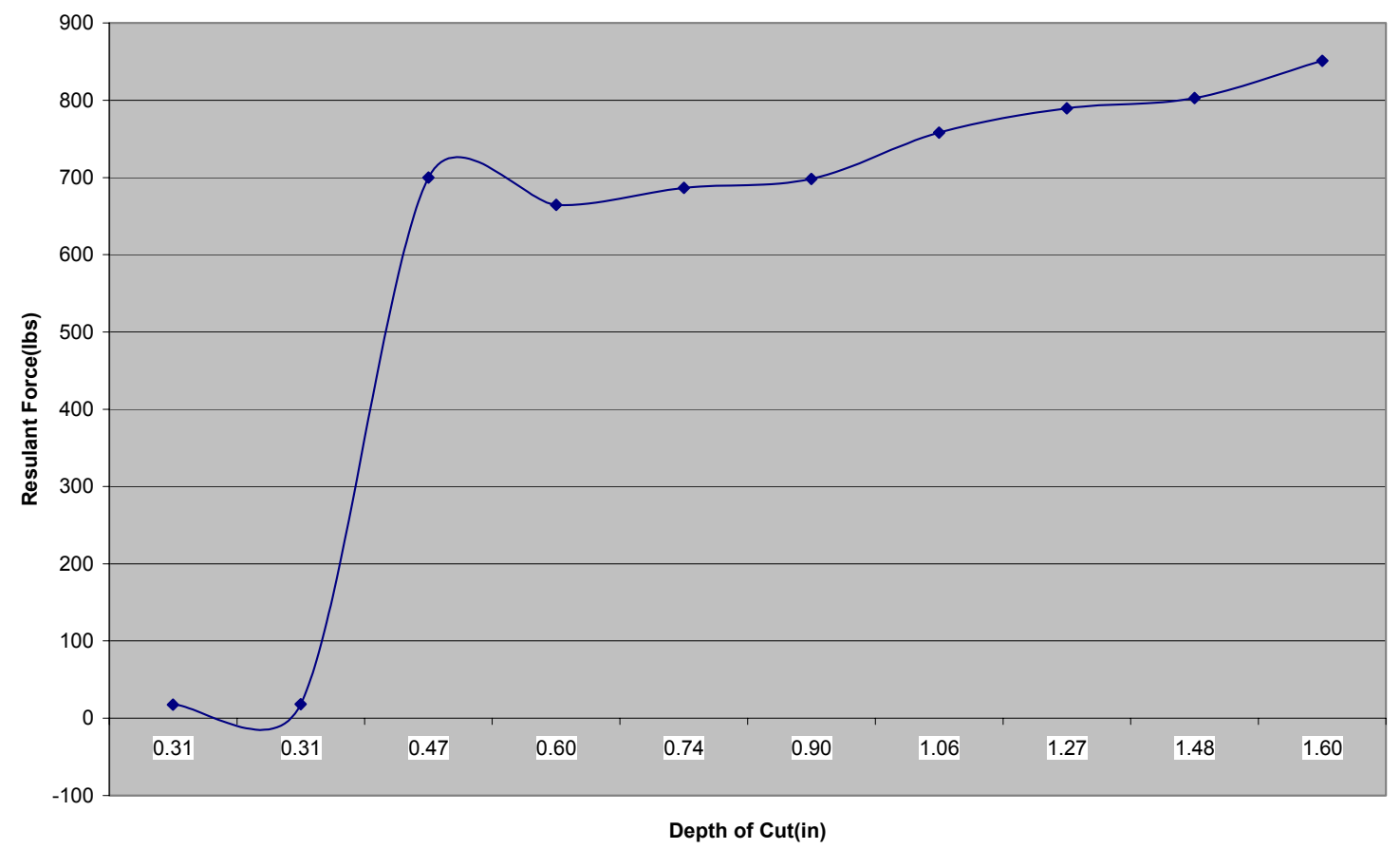

Fig 4.12 Graph showing resultant force for bit D 
Penetration Vs Depth of Cut(U76K)

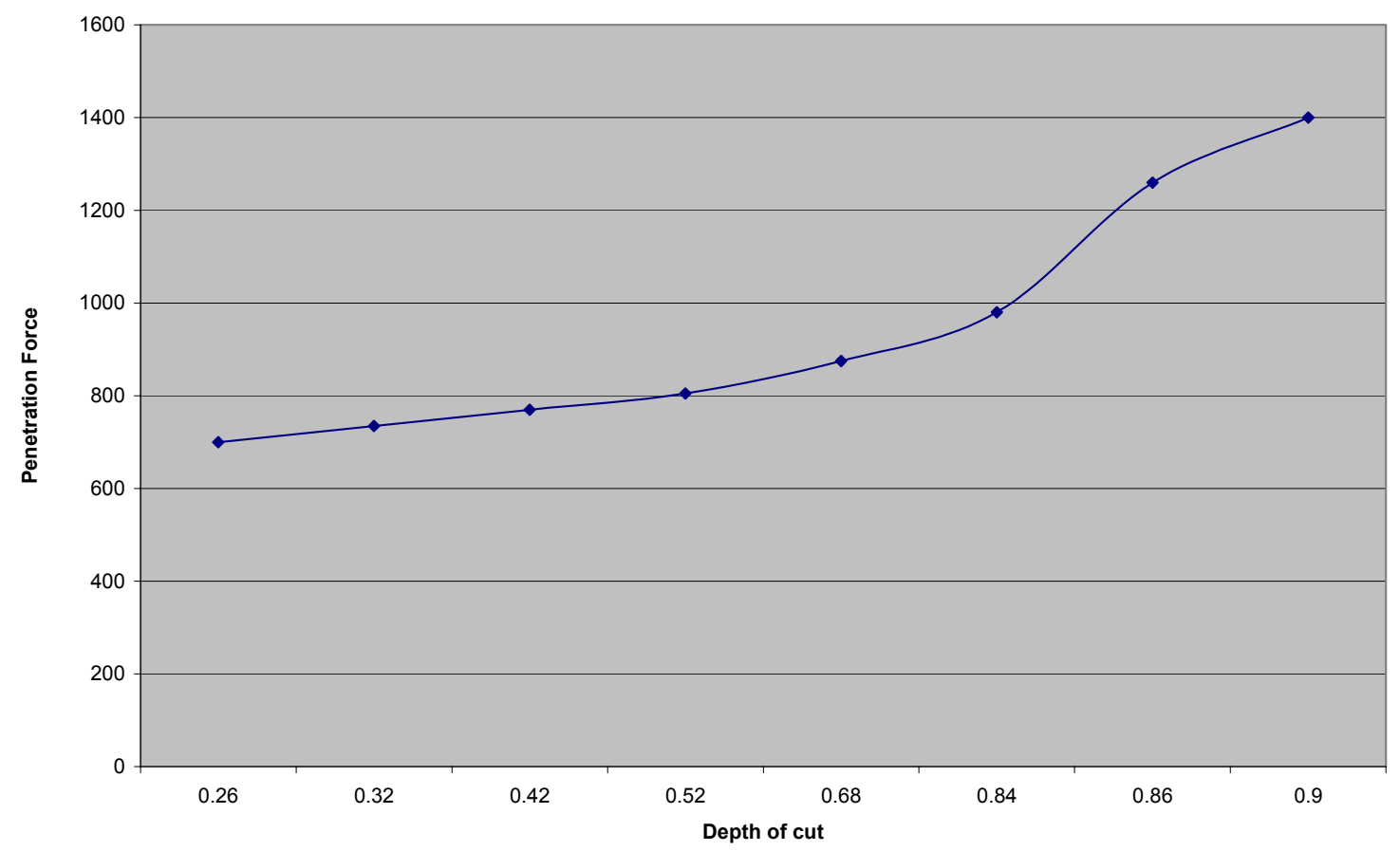

Fig 4.13 Graph showing penetration force for bit U76K 
Cutting Force VS Depth of Cut(U76K)

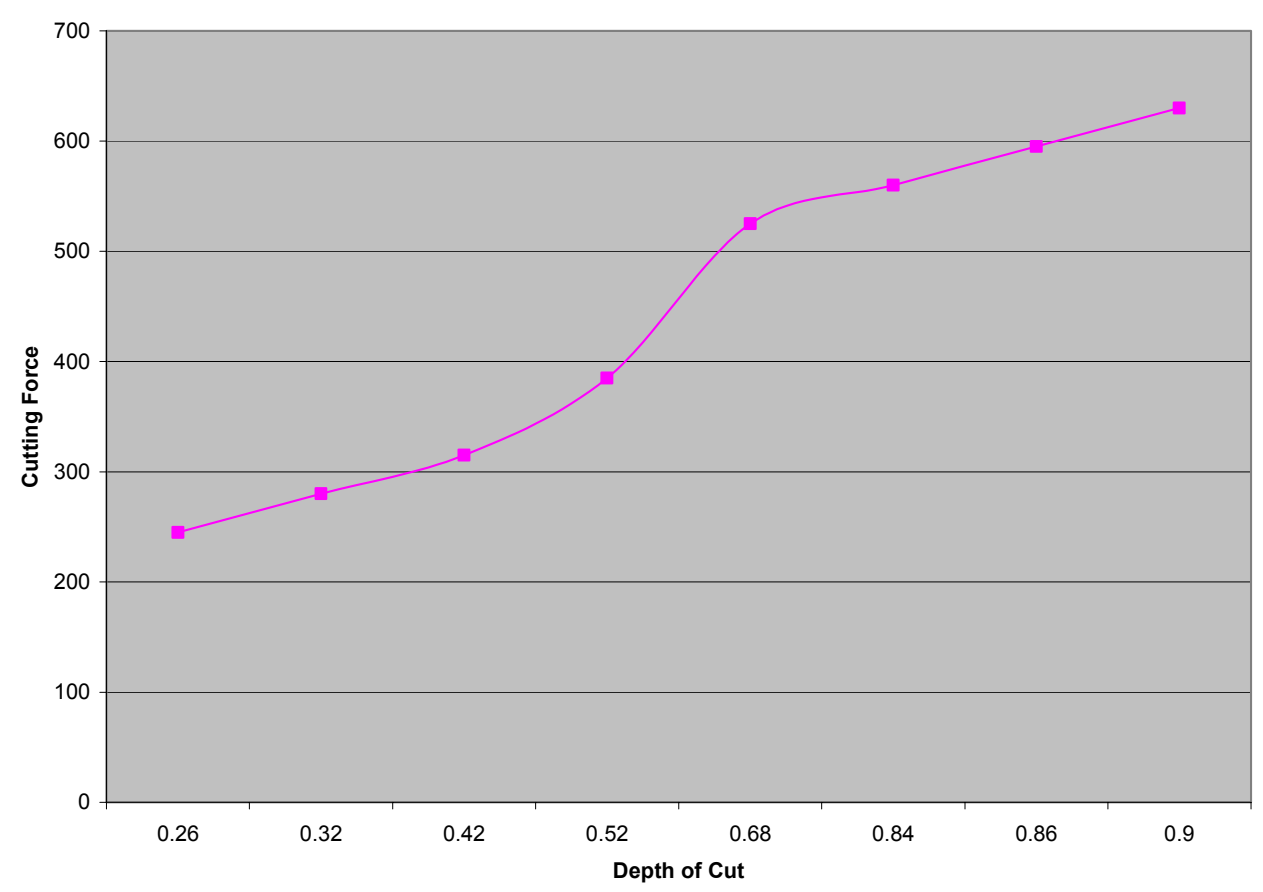

Fig 4.14 Graph showing cutting force for bit U76K 
Resultant Force Depth of Cut U76K

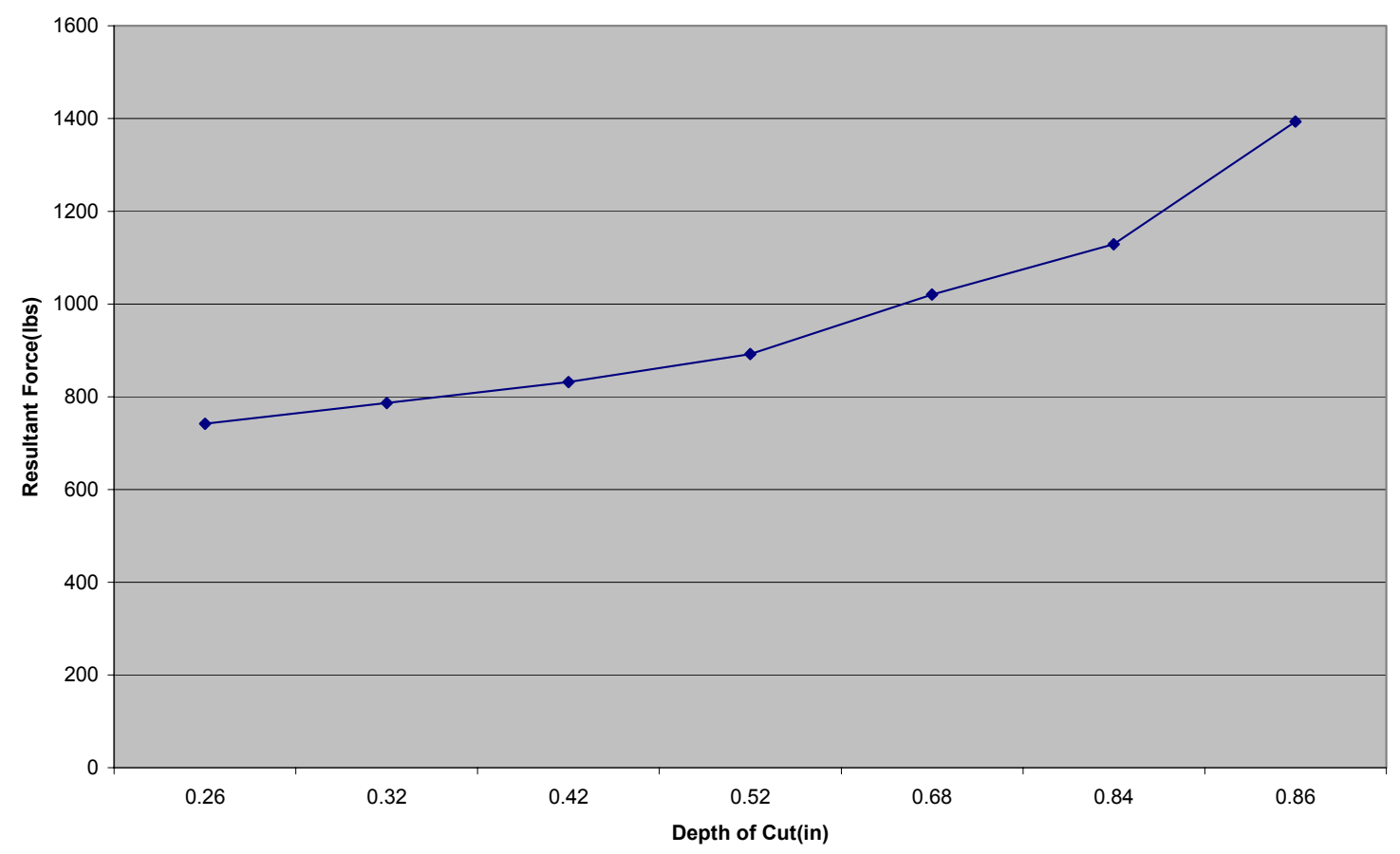

Fig 4.15 Graph showing resultant force for bit U76K 
Penetration Force for all Bits

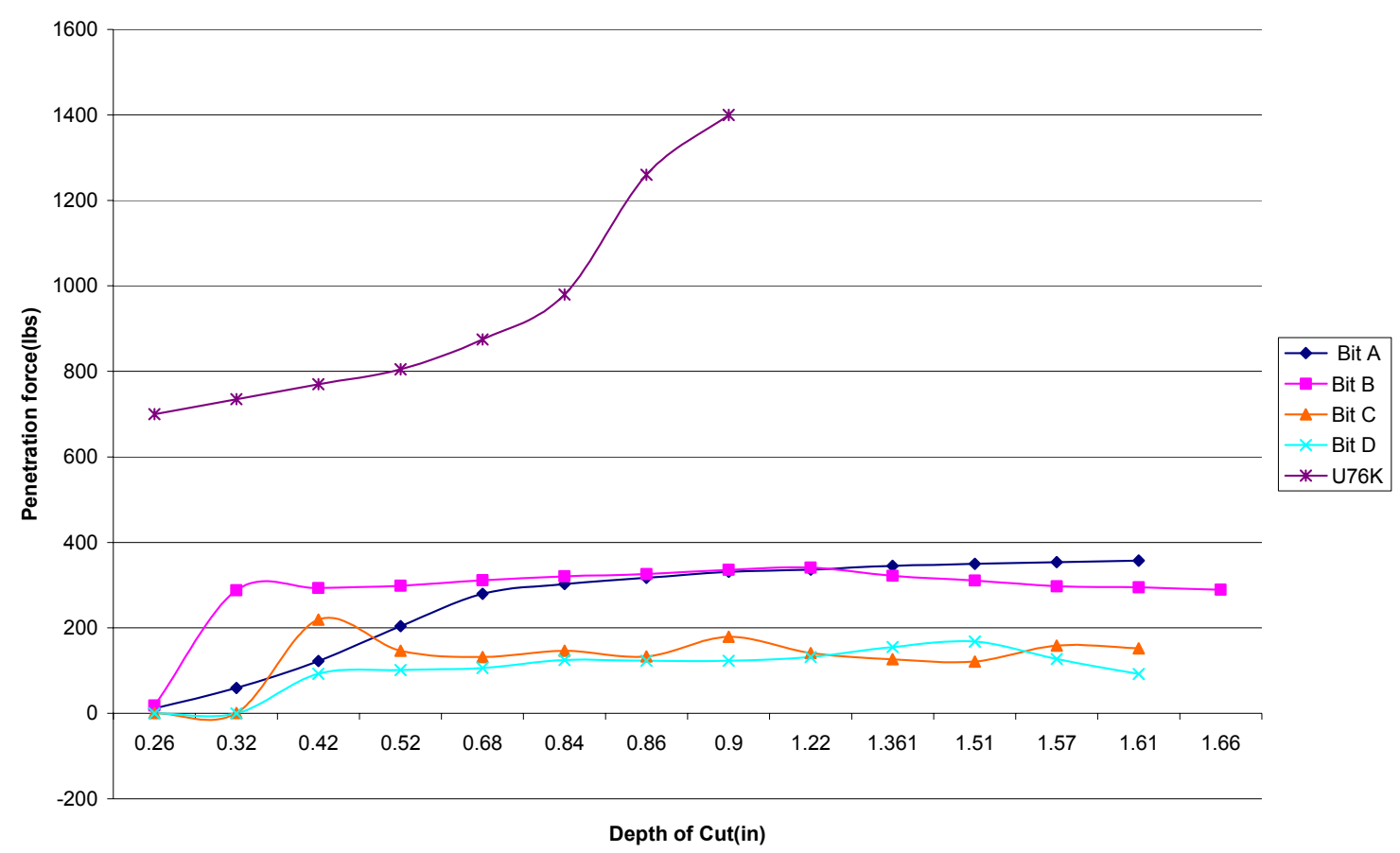

Fig. 4.16 Graph showing penetration force for all bits 
Cutting Force for all Bits

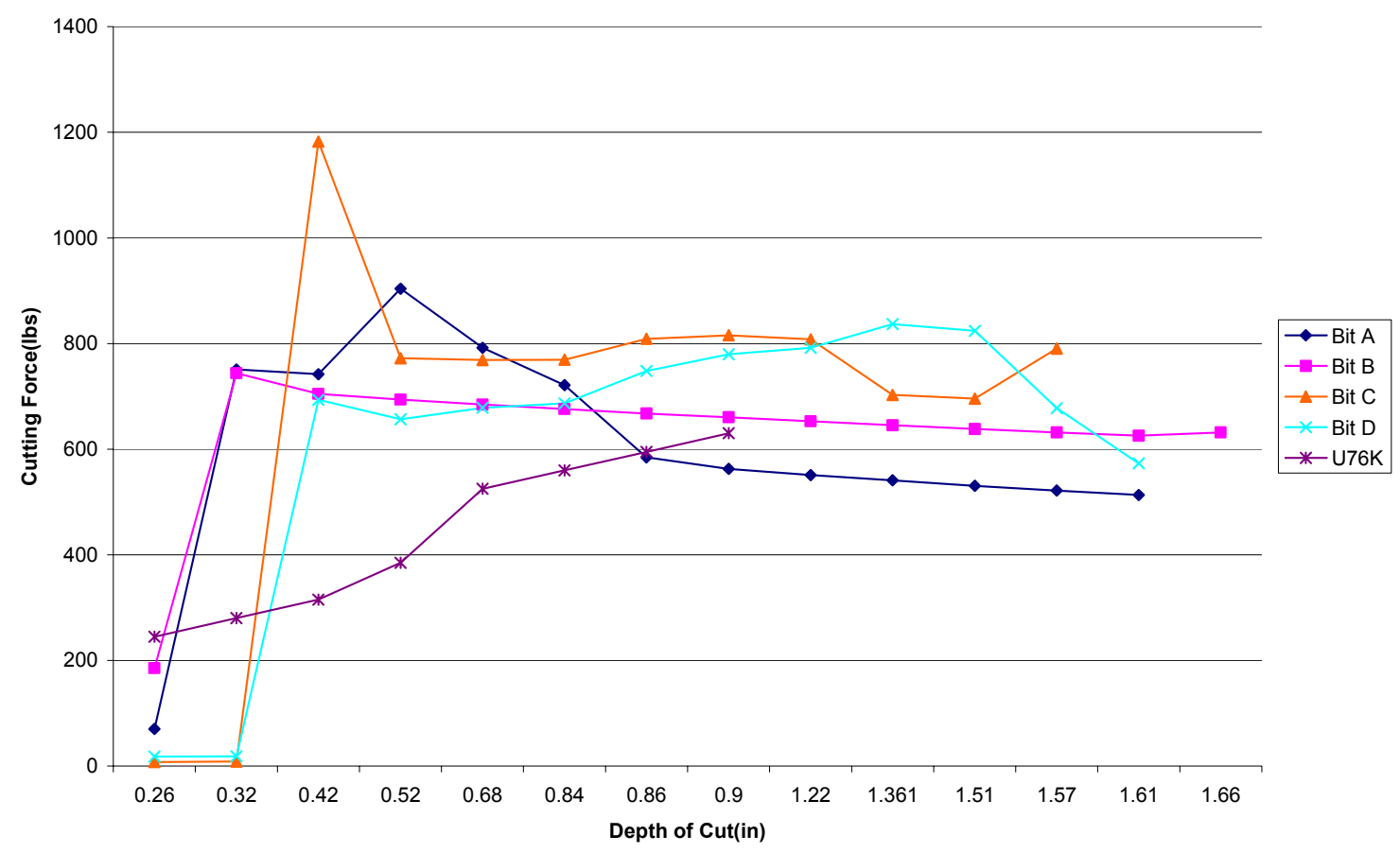

Fig. 4.17 Graph showing cutting force for all bits 
Resultant Force for all Five Bits

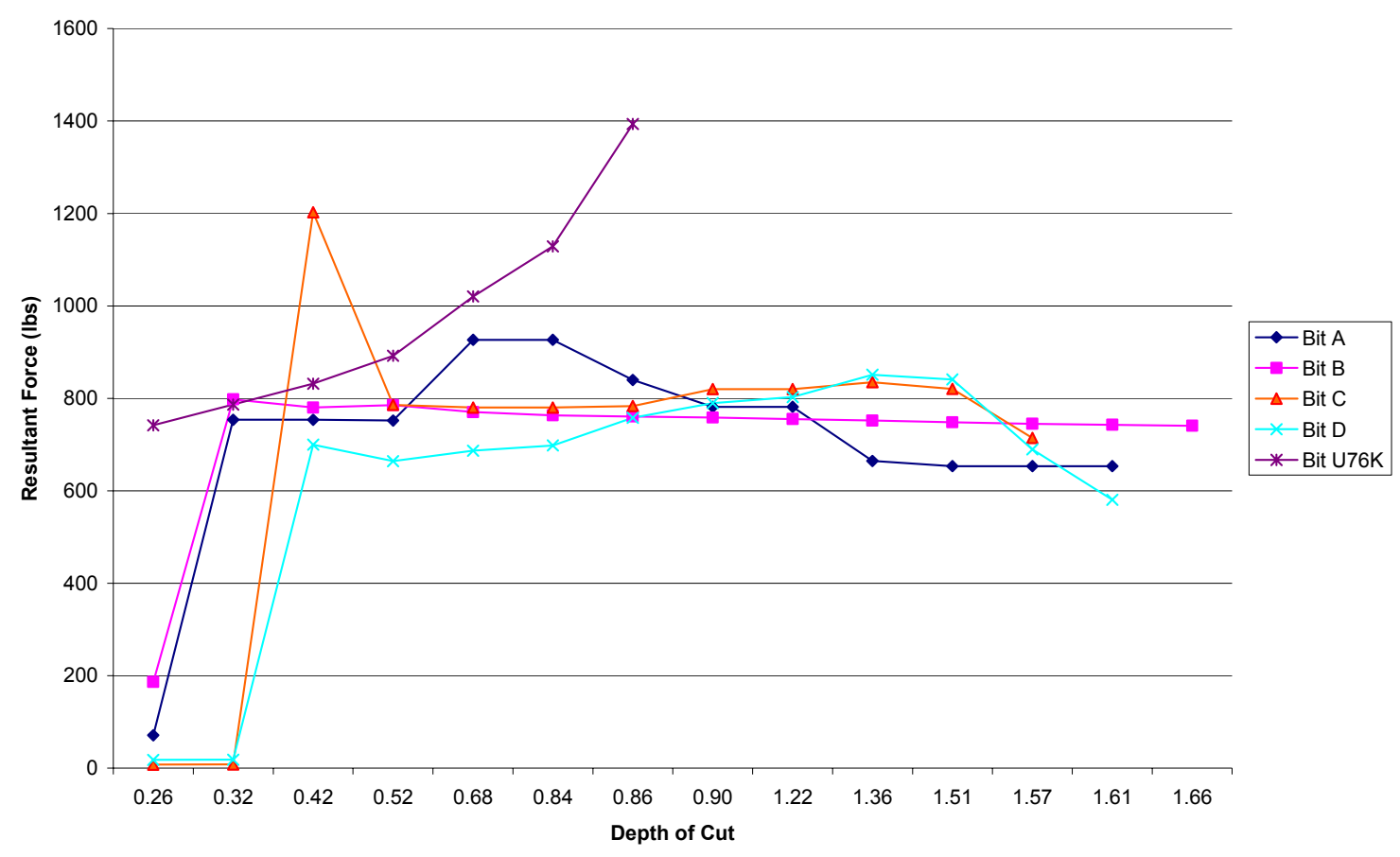

Fig. 4.18 Graph showing resultant force for all bits 
Specific Dust for all 5 Bits Compared

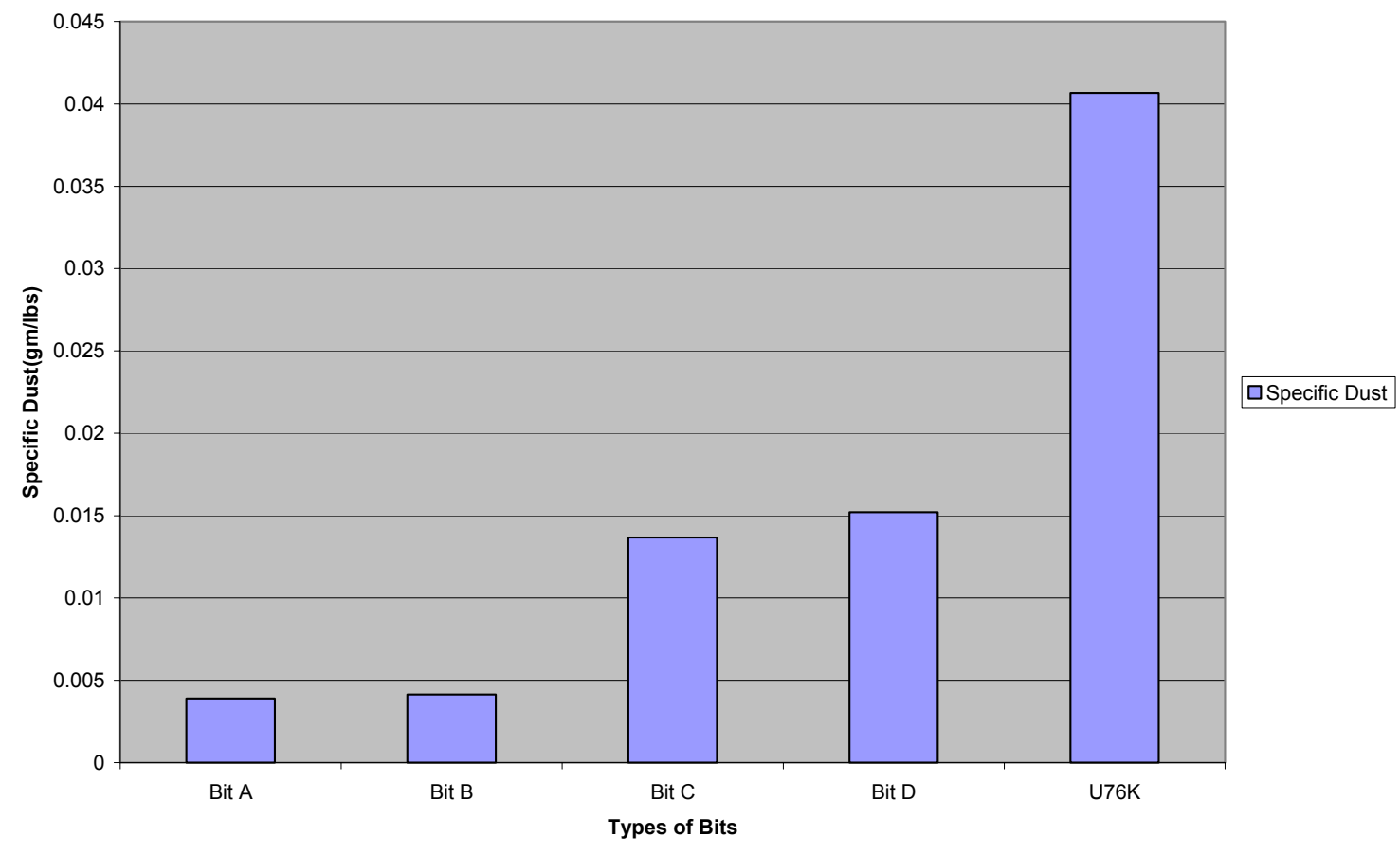

Fig. 4.19 Graph showing specific dust for all bits 


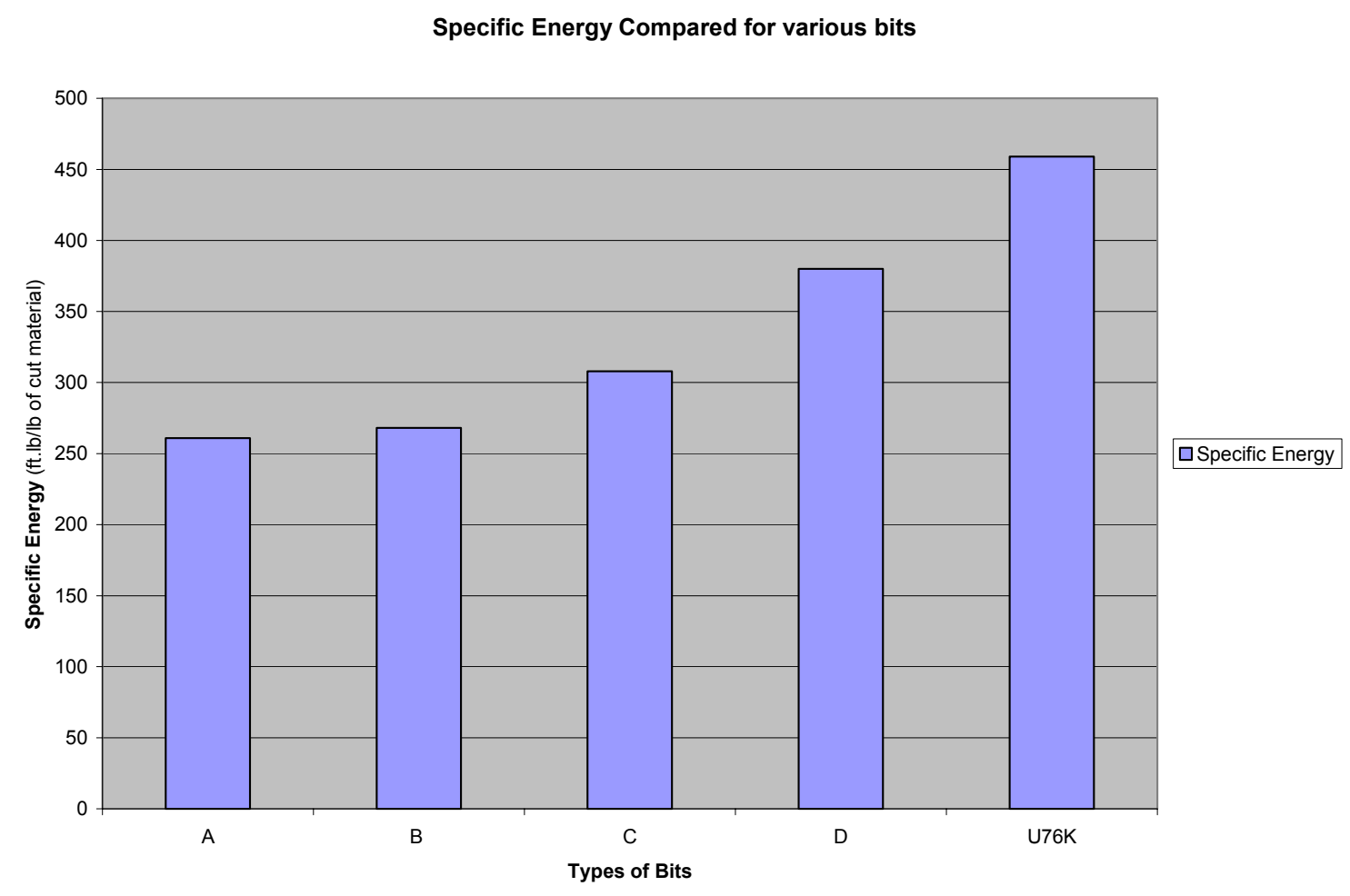

Fig. 4.20 Graph showing the specific energy for all bits

\subsection{Analysis}

Assessment of the bit-rock interaction reveals a significant number of parameters affecting design of cutting tool. These findings are summarized as follows 
1. The magnitude of cutting and penetration forces is dependent on the area of contact between the bits and the rock. The smaller the bit, the smaller is the area of contact between bit and rock, increases stress concentration for a given machine power, hence reduces cutting and penetration forces.

2. Larger bit tip imposes more damage to the rock, results in more fracture and decreases specific energy during cutting, particularly in multi bit interaction, provided depth of cut to bit spacing is optimum.

3. An optimum area of contact is essential in order to have sufficient bit penetration and prolong the life of the bit. That is to say that small bit will not last too long, while a larger bit limits bit penetration and causes machine vibration.

4. U76K is a typical bit design commonly used in the coal industry. Assessment of this bit indicated that the bit tip/nose is almost submerged in the bit cone. At very shallow depth of cut only the tip of the nose is in contact and results in less energy consumption. After a limited penetration approximately 0.25 in the bit cone become in contact with the rock and results in much more specific energy consumption and limits bit penetration as it can be seen in figure 4.13-4.18, the bits only penetrate to 0.9 inches, further penetration is beyond the capability of the ARCCS available power. This type of the design reduces interface stress concentration between the bits and the rock, limits bit penetration, increases resultant forces, increases specific energy and specific dust abrasion of the bit cone with the rock. 


\subsection{Conclusions}

It is obvious from the results that the resultant force is the highest on the bit U76K because of improper bit tip and cone design. This improper bit and cone arrangement has also affected the amount of dust generation mainly due to abrasive interaction of bit and rock. As the bit tip and bit cone size and arrangements are changed in the case of bit A-D, the resultant forces are varied for each bit depending upon the size of the bit tips and fracture imposed by bit to the rock. The relative position of the bit tip is also very significant, both for stress concentration and abrasive reaction. The larger bits results in higher resultant forces during cutting. However the specific dust and specific energy are in general opposite with respect to resultant forces. The larger bit tip causes more fracture on the cutting material, hence more material is removed and require less specific energy and with less bit body contact it will produces less specific dust. Stream lining of bit tip as bit cone and cylindrical bit cone is important element in bit design. Further more the extended slope angle of the bit tip should not intersect the bit cone. This design limits interaction of bit cone with rock, hence reduces/eliminates abrasion and crushing of the bit cone on the ridges/wall of the bit path/grove.

\subsection{Recommendations}

Only limited numbers of experiments have been carried out in this research. A detailed and more comprehensive study is needed in order to evaluate precisely the effects of bit geometry in multiple bit-rock/coal interaction. The comprehensive study will enable one to make parametric study of bit geometry to determine the bit geometric parameters for cutting rock/coal. 


\section{References:}

1. Organiscak,J.A.et al.,(1990), Sources and Characteristics of Quartz Dust in Coal mines, Proceedings of3rd Symposium on the Respirable Dust in the Mineral Industries, October 17-19, 1990, Pittsburgh, PA, pp. 319-328.

2. Kissel, F .N ., (1987), USBM's Dust Control and Ventilation Research Program, A seminar presented at the Mining Engineering Department of West Virginia University, September 16, 1987.

3. Hinds, W.C., Aerosol Technology, John Wiley \& Sons Publishers, New York, New York, pp. 221-226.

4. U.S. Department of Labor, National Institute of Occupational Safety and Health, A Guide to working safely with Silica, 1997, pp.551-664.

5. Reddy, N.P., 1998, Characterization of Coal Breakage by Continuous Miners, Ph.D. dissertation, Department of Mining Engineering, WVU, Morgantown, WV , 184pp.

6. Khair, A. W., Xu, D., and Ahmad, M., "Principles of Bit Wear and Dust Generation", Proceedings of new Technology in Mine Health and Safety, SME, Littleton, CO, Febrauary 1992, pp.175-183.

7. Khair, A. W ., Xu, D., "Mechanism of Regrinding in Rotary Cutting Machine", Proceedings of the Symposium on Respirable Dust in the Mineral Industries, Vista International Hotel, Pittsburgh, P A, Dct 17-19,1990, pp. 329-337.

8. Khair, A. W., Xu, D., "Laboratory approach to study dust generation due to regrinding", Proceedings of5th U.S. Mine Ventilation Symposium, SME Publisher, Littleton, CD, 1991, West Virginia University, Morgantown, WV , June 3-5, 1991, pp. 215-224.

9. Matta, J.E., "Effect of Location and type of water sprays for respirable dust suppression on a continuous mining machine", USBM TPR 96, 1976, 11 pp.

10. Roepke, W.W., Lindroth, D.P., and Myren, T.A., (1976), "Reduction of Dust and Energy During Coal Cutting Using Point Attack Bits With Rotary Drum tested and produced the same or less, $-0.32 \mathrm{~cm}(-1 / 8$ in.)product.

11. Roepke, W.W., and Hanson, B.D., (1983), "Effect of Asymmetric Wear of Point Attack Bits on Coal Cutting Parameters and Primary Dust Generation", USBM, RI 8761, 16pp.

12. Barker, J.S., 1964, "A Laboratory Investigation of Rock Cutting Using Large Picks," International Journal of Rock Mechanics and Mining Sciences, Vol. 1, pp. 519-534.

13. Pomery C.D., and Brown, J.H., 1968, "Laboratory InV-5.§tigation of Cutting Process Applied to Coal Winning Machines," Journal of Strain Analysis, Vol. 3, No.3, pp.232-243.

14. Khair, A. W., Reddy, N.P., and Quinn, M.K., "Mechanism of Coal fragmentation by continous miner", Journal of Mining Science and Technology, March 1998, pp. 189-214.

15. Roepke, W. W ., et al., ( 1995), Improved Performance of Linear Coal Cutting Compared with Rotary Cutting, USBM, RI 9536, pp.34. 
16. Organiscak,J.A., Khair, A. W., and Ahmad, M., Studies of Bit Wear and Respirable Dust Generation, SME -AIME Annual meeting and exhibit, Denver, CO, March 6-9, 1995, Preprint no.95-214. Also in SME Mining Transactions/Annual Bound, Vol. 298, 1995, pp. 1874-1879.

17. Khair, A.W., "The effects of bit geometry on rock cutting efficiency", Applied occupational and Environmental Hygiene, Vol.11, Number. \&, July 1996, pp695700.

18. V. B. Achanti and A. W. Khair, Laboratory Assessment of Rock Fragmentation Process by Continous miners, SME-AIME Annual Meeting and Exhibit, Denver, CO, February 24-27, 1997, preprint No. 97-172. Also in SME, Mining Engineering Journal, March 1998, pp. 75-80.

19. H.W. Shen, H. R. Hardy, Jr., and A. W. Khair, Laboratory Study of Acoustic Emission and Particle Size Distribution During Rotary Cutting, Intl. J. Rock Mech. \& Min. Sci., vol. 34, No. 3-4, 1997, Paper No. 121.

20. V. B. Achanti and A. W. Khair, Bit geometry Effects on Failure Characteristics of rock, SME-AIME Annual Meeting and Exhibit, Orlando, Florida, March 9-11, 1998. Also in SME, Mining Engineering Journal, June 2000, pp. 101-107.

21. A. W. Khair, J. Szymkowski, and F. Bienia, The Effects of Indentor Angle on Fracture Intensity - A Qualitative Assessment of the Design to Reduce Respirable Dust, Proc. International Conference on Control of Dust Hazards in the Mining Industry, Wisla, Poland, October 5-7 1999, 10 pp.

22. A. W. Khair, S. Addala, C. Pezowicz, and M. Bernakiewicz, Fracture Process in Rock by Wedge Indentors Utilizing Holographic Interferometry, proc. of the Fourth North American Rock Mechanics Symposium NARMS 2000, Seattle, WA, USA, July 31-August 3, 2000, pp.41-47.

23. A.W. Khair, , S. Addala and C. Pezowicz, Effect of Cutting Tool Angle on Failure Mechanism of Rock - Tool Interaction, Proc. of the Ninth International Symposium on Mine Planning and Equipment Selection, Athens, Greece, November 6-9, 2000, 601-606 pp.

24. Srikanth Addala, 2000, Relationship between Cutting Parameters and Bit Geometry in Rotary Cutting, Masters Thesis, Department of Mining Engineering, WVU, Morgantown, WV.

25. S. Addala, A. W. Khair, and M. Venkataraman, Relationship Between Cutting Parameters and Bit Geometry in Rotary Cutting of Rocks, Proc. of International Conference of Mining Techniques 2001, Karakow-Krynica, Wrezesian, Poland September 18-21, 2001, pp. 567-581.

26. V. B. Achanti and A. W. Khair, Cutting Efficiency Through Optimized Bit Configuration - An Experimental Study Using A Simulated Continuous Miner, Mineral Resources Engineering (MRE) Journal, Imperial College Press, London, UK, Vol. 10, 4 (2001) pp. 427-434

27. A. W. Khair, Research and Innovations for Continuous Miner's Cutting Head for Efficient Cutting Process of Rock/Coal (an invited paper), Proc. of the $17^{\text {th }}$ International Mining Congress of Turkey, Ankara, Turkey, June 19-22, 2001, pp.45-55. 
28. M. Venkataraman and A. W. Khair, Effects of rate of Sumping on Fragmentation Process in Laboratory Rotary Cutting Simulator, Proc. $2^{\text {nd }}$ International Conference of Mining Technique 2002, Karakow - Krynica, Poland, September, 2002, pp.7-18.

29. Khair, A. W., and Achanti, V .B., Experimental Investigation of Rock Fragmentation Efficiency of a Simulated Wet-Drum Continuous Miner, Proceedings of Pacific Rim International Conference on Water Jet Technology, New Delhi, India, Feb. 3-5,1998, pp. 460-466.

30. Khair, A. W ., and Achanti, V .B., Current trends in Water Jet Cutting Applications to Geotechnical Industry in USA, Proceedings of International Conference on High Pressure Science and Technology, Kyoto, Japan, August 2529, 1997, 6pp.

31. V.B. Achanti and A.W. Khair, A Nomograph Based Method for Selecting Rock Cutting Parameters on a Simulated Continuous Miner, Proc. SARocks '98, II Brazilian Symposium in Rock Mechanics, $5^{\text {th }}$ South American Congress on Rock Mechanics which was held in Santos, Brazil, November 1998, pp.295-300.

32. A. W. Khair, B. Yu, and M. Venkataraman, An Approach to Optimization of a continuous Miners Cutting Head- Using Numerical and Experimental Studies, 2002 SME-AIME Annual Meeting and Exhibit, Phoenix, Arizona February 2427, 2002. Preprint Number 01-181, 12pp.

33. B. Yu and A. W. Khair, Numerical Simulation of the Effects of Cutting Parameters on Rock/Coal Fragmentation, Proc. $2^{\text {nd }}$ International Conference Mining Techniques 2002, Krakow - Krynica, Poland, Sept. 2002. pp1-6

34. A.W. Khair, The Effect of Bit Geometry and Size on Cutting Parameters in Linear Cutting, Submitted for publication in mineral Resources Engineering (MRE) Journal, Imperial College Press, London, UK.

35. B. Yu and A. W. Khair, Effects of Dynamic Bit Impact and Contact on Rock, ISRM International Symposium on Rock Engineering for Mountain Regions, EUROCK, 2002, Fundhal, Portugal, November 25-28, pp 475-480.

36. Reddy, N.P., 1988, " Characterization of coal Breakage by Continuous Miners", $\mathrm{Ph} . D$. dissertation, Department of Mining Engineering, West Virginia University, Morgantown, 184pp. 